\title{
Applying low-salinity water to alter wettability in carbonate oil reservoirs: an experimental study
}

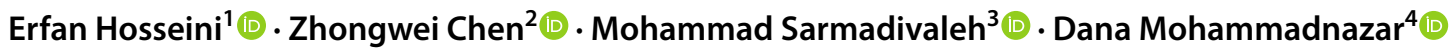

Received: 13 April 2020 / Accepted: 6 October 2020 / Published online: 23 October 2020

(c) The Author(s) 2020

\begin{abstract}
Seawater has been widely used as an injection fluid for maintaining pressure in sandstone and carbonate reservoirs. In the literature related to EOR research, it was noted that diluted seawater (low-salinity water) can highly improve recovery due to the specific ions (such as $\mathrm{Ca}^{2+}, \mathrm{Mg}^{2+}$, and $\mathrm{SO}_{4}{ }^{2-}$ ). Such conclusions lead to the application of "Smart Water" in which changing the ion composition of injected water alters wettability and enhances recovery. Although many theories have been established to explain the mechanism of this phenomenon, almost all of them are limited to sandstone rocks, and the impact of smart water on carbonated reservoirs has rarely been explored. This study experimentally investigates the impact of the injection of high- and low-salinity and smart water on the change of wettability and recovery improvement in an Iranian South oil reservoir. Two different sets of experimental work were conducted. In the first set of experiments, the effect of formation water, diluted formation water (from 223,969 to $5000 \mathrm{ppm}$ and $2000 \mathrm{ppm}$ ), seawater (initially 51,400 ppm), and diluted seawater on wettability alteration is investigated by monitoring the contact angle and relative permeability variation. The results showed that dilution of seawater to $2000 \mathrm{ppm}$ has the most impact on wettability alteration. The relative permeability changed, and the contact angle decreased by a significant value of $100^{\circ}$, and recovery increased by about $71 \%$. In the second set, the effect of ion change on the result was studied. For this purpose, the sulfate ion of diluted seawater (2000 ppm) is substituted by phosphate ion $\left(\mathrm{H}_{2} \mathrm{PO}_{4}^{-}\right)$. The results show the wettability alteration similar to the sulfate one. This study sheds light on the possible mechanism of wettability alteration in the carbonate reservoir, and the result will help to design a better low-salinity injection scenario.
\end{abstract}

Keywords Wettability alteration $\cdot$ Contact angle $\cdot$ Relative permeability $\cdot$ Low salinity $\cdot$ Recovery

$\begin{array}{ll}\text { Abbreviations } \\ \text { FW } & \text { Formation water } \\ \text { SW } & \text { Seawater } \\ \text { TDS } & \text { Total dissolved solids }(\mathrm{mg} / \mathrm{l}) \\ \text { LowSal } & \text { Low-salinity water } \\ \text { SW5000 } & \text { Seawater diluted to TDS }=5000 \mathrm{mg} / \mathrm{l}\end{array}$

Erfan Hosseini

e.hosseini19@gmail.com

1 Department of Petroleum Engineering, Sarvak Azar Engineering, and Development (SAED) Company, Oil Industries Engineering and Construction (OIEC) Group, Tehran, Iran

2 School of Mechanical and Mining Engineering, Queensland University (UQ), Brisbane, Australia

3 Department of Petroleum Engineering, Curtin University, Perth, Australia

4 Department of Polymer Chemistry, Islamic Azad University, Shahreza, Iran
SW2000 Seawater diluted to TDS $=2000 \mathrm{mg} / \mathrm{l}$

FW5000 Formation water diluted to TDS $=5000 \mathrm{mg} / \mathrm{l}$

FW2000 Formation water diluted to TDS $=2000 \mathrm{mg} / \mathrm{l}$

SSW2000 Synthetic seawater diluted to TDS $=2000$ $\mathrm{mg} / \mathrm{l}$

SW0.5S Synthetic brine with the composition of seawater except for substitute phosphate ion instead of sulfate with the concentration of half of the sulfate diluted to $2000 \mathrm{ppm}$

SW1S Synthetic brine with the composition of seawater except for substitute phosphate ion instead of sulfate with the concentration of equal to sulfate, diluted to $2000 \mathrm{ppm}$

SW2S Synthetic brine with the composition of seawater except for substitute phosphate ion instead of sulfate with concentration of two times sulfate, diluted to $2000 \mathrm{ppm}$

CA Core plug with core ID: A

CB Core plug with core ID: B 
CAA Core plug with core ID: AA

CBB Core plug with core ID: BB

\section{List of symbols}

$\mu \quad$ Dynamic viscosity (cp)

$\theta \quad$ Contact angle $\left({ }^{\circ}\right)$

$S_{\text {wi }} \quad$ Initial water saturation

$S_{\text {or }} \quad$ Residual oil saturation

$L \quad$ Core plug length $(\mathrm{cm})$

$\mathrm{C} / \mathrm{CO}$ The ratio of outflow concentration divided by inflow concentration

\section{Introduction}

Oil and gas still play a critical and fundamental role in securing world energy supplies (Sun et al. 2020). The consumption of oil and gas increases as the world energy demand increases daily (Souraki et al. 2018). Enhanced oil recovery (EOR) is one of the most effective solutions to keep the production rate high enough to address the demand (Zolfagharloo et al. 2018). It is estimated that $40 \%$ of the world's total hydrocarbon production is from carbonate rocks (Atthawutthisin 2012). The Ghawar and South Pars/North Dome fields (located in the Persian Gulf) are the world's largest oil and gas fields, respectively, that are composed of carbonate rocks (Austad et al. 2005). Smart water is a modified injection brine specially designed for inducing wettability alteration to improve the oil recovery, and it can be injected in both secondary and tertiary (EOR) production phases (Amirian et al. 2017). The previous studies showed that diluted seawater and formation water can change the wettability of reservoir rocks and therefore the EOR performance (Austad et al. 2010). Low-salinity and smart water are an appropriate choice for EOR economically. So lots of works had been done at laboratory and field scale (e.g., Eftekhari 2019; Taheriotaghsara et al. 2020), and some companies performed field-scale injection of low-salinity or smart water. British Petroleum as an example is the pioneer of this treatment, and they registered the LowSal ${ }^{\mathrm{TM}}$ trademark (REF). Statoil is also very active in the field implementation of LowSal technology (REF). In the Middle East, the National Iranian Oil Company (NIOC) and Saudi Aramco conducted laboratory and/or field studies (REF). Laboratory studies showed that $5000 \mathrm{ppm}$ salinity is the point that most wettability alteration occurs (Bartels et al. 2019). Many mechanisms were suggested to explain this phenomenon. The most important one is the multi-ion exchange and double-layer effect. It is believed that $\mathrm{Ca}^{2+}, \mathrm{Mg}^{2+}$, and $\mathrm{SO}_{4}{ }^{2-}$ ions are the active ions that participate in wettability alteration by separating the carboxylate groups from the surface of rock (Berg et al. 2010). Amirian et al. (2017) results showed that the wettability alteration was observed after injecting low-salinity water
(LSW) into oil-wet systems and the wettability status shifted toward more water-wet. Hosseini et al. (2018) experimentally investigated the EOR using low-salinity water and nanoparticles in a carbonate reservoir. They concluded that the value of IFT decreases as the concentration of magnesium is increased and the effect of calcium ion concentration change is negligible. Also, in low total dissolved solids (TDS), the value of IFT increases with an increase in $\mathrm{Na}^{+}$ion. In high TDS, they observed a negligible change in IFT. They also showed that (high TDS, i.e., 40,000 ppm) the wettability alteration decreases by increasing the calcium ion concentration which is opposite in lower TDS (5000-20,000 ppm) cases. Amirian et al. (2019) investigated the impact of different clay minerals and the nature of cations on the lowsalinity effect (LSE) using microfluidics and geochemical modeling. They concluded that $\mathrm{Ca}^{2+}$ cations present in the residential water did not have much impact on LSE. The numerical model also predicted an insignificant change in the zeta potential under experimental conditions. The effect of $\mathrm{Ca}^{2+}$ ions on LSW injection was also investigated by AlSarihi et al. (2019). They performed laboratory core floods with a variation in the sodium and calcium concentrations in the injected brine. Their results showed that some $\mathrm{Ca}^{2+}$ ions were released during the $\mathrm{NaCl}$ injection, suggesting competitive adsorption of $\mathrm{Na}^{+}$and $\mathrm{Ca}^{2+}$ ions on the clay and residual adsorbed $\mathrm{Ca}^{2+}$ concentration after the deionized water (DIW) injection. This work is a case study focusing on one of the Iranian oil fields to investigate the impact of salinity and composition of injected water on the EOR recovery. All experimental parameters, crude oil, core plugs, contact angle discs, and formation brine are all from this reservoir. The main objective of this work is to determine the possibility of using low-salinity and smart water as a tool for wettability alteration. Also, because of uncertainty at the mechanism of wettability alteration at carbonated reservoirs, it had been decided to investigate the ion and $\mathrm{pH}$ alteration to re-check the mechanism. Elimination of sulfate ion and substitution with phosphate ion was the next step to challenge the mechanism.

\section{Material characterization}

\section{Core characterization}

Five-inch cores were taken from one of the offshore Iranian oil fields in the Persian Gulf. Two core plugs $(38.10 \mathrm{~mm}$ in diameter and $91.00 \mathrm{~mm}$ in length) were cut and cleaned. The routine core analyses (RCAL) were performed on each sample, and the results are summarized in Table 1. Core samples A and B were used simultaneously in all experimental procedures. For a better understanding of rock-fluid interaction, 
Table 1 Core sample properties used in this study

\begin{tabular}{llllllll}
\hline Core plug & Depth $(\mathrm{m})$ & Length $(\mathrm{mm})$ & Diameter $(\mathrm{mm})$ & P.V $(\mathrm{ml})$ & $\varnothing(\%)$ & $\begin{array}{l}\text { Water perme- } \\
\text { ability }(\mathrm{mD})\end{array}$ & $S_{\text {wi }}(\%)$ \\
\hline A & 2629.3 & 91.00 & 37.05 & 18.12 & 18.48 & 1.78 & 24.32 \\
B & 2648.5 & 89.97 & 36.99 & 12.7 & 13.13 & 0.63 & 29.13 \\
\hline
\end{tabular}

Table 2 Analysis results of XRD test of sample A

\begin{tabular}{llll}
\hline Sample & Major phase (s) & Minor phase (s) & Trace phase (s) \\
\hline $\mathrm{A}$ & Dolomite (36-0426) & - & Quartz (33-1161) \\
$\mathrm{kV}=40$ & $\mathrm{CaMg}\left(\mathrm{CO}_{3}\right)_{2}$ & $\mathrm{SiO}_{2}$ \\
$\mathrm{~mA}=30$ & Calcite (05-0586) & \\
$\mathrm{Ka} .=\mathrm{Cu}$ & $\mathrm{CaCO}_{3}$ & \\
Fil. $=\mathrm{Ni}$ & & \\
\hline
\end{tabular}

Table 3 Results of XRD test of sample B

\begin{tabular}{llll}
\hline Sample & Major phase (s) & Minor phase (s) & Trace phase (s) \\
\hline $\mathrm{B}$ & Calcite (05-0586) & Dolomite (36-0426) & - \\
$\mathrm{kV}=40$ & $\mathrm{CaCO}_{3}$ & $\mathrm{CaMg}\left(\mathrm{CO}_{3}\right)_{2}$ & \\
$\mathrm{~mA}=30$ & & \\
$\mathrm{Ka} .=\mathrm{Cu}$ & & \\
Fil. $=\mathrm{Ni}$ & & \\
\hline
\end{tabular}

X-ray diffraction (XRD) test was applied on samples A and B (Tables 2 and 3, and Figs. 1 and 2).

\section{Crude oil characterization}

The crude oil was pre-filtered through a Whatman 42 filter paper before it was used in the experiments to separate possible sand and small particles that may plug pore throats. The component and physical fluid properties of the given crude oil sample are shown in Tables 4 and 5, respectively. Also, using IP 180 standard method, it was found that the asphaltene content is $10.3 \%$.

\section{Brine characterization}

Compositions of the synthetic formation water (FW) and seawater (SW) from the Persian Gulf are given in Table 6. To synthesize FW, brine was prepared using Merck Millipore Company's salts. By considering the solubility of salts

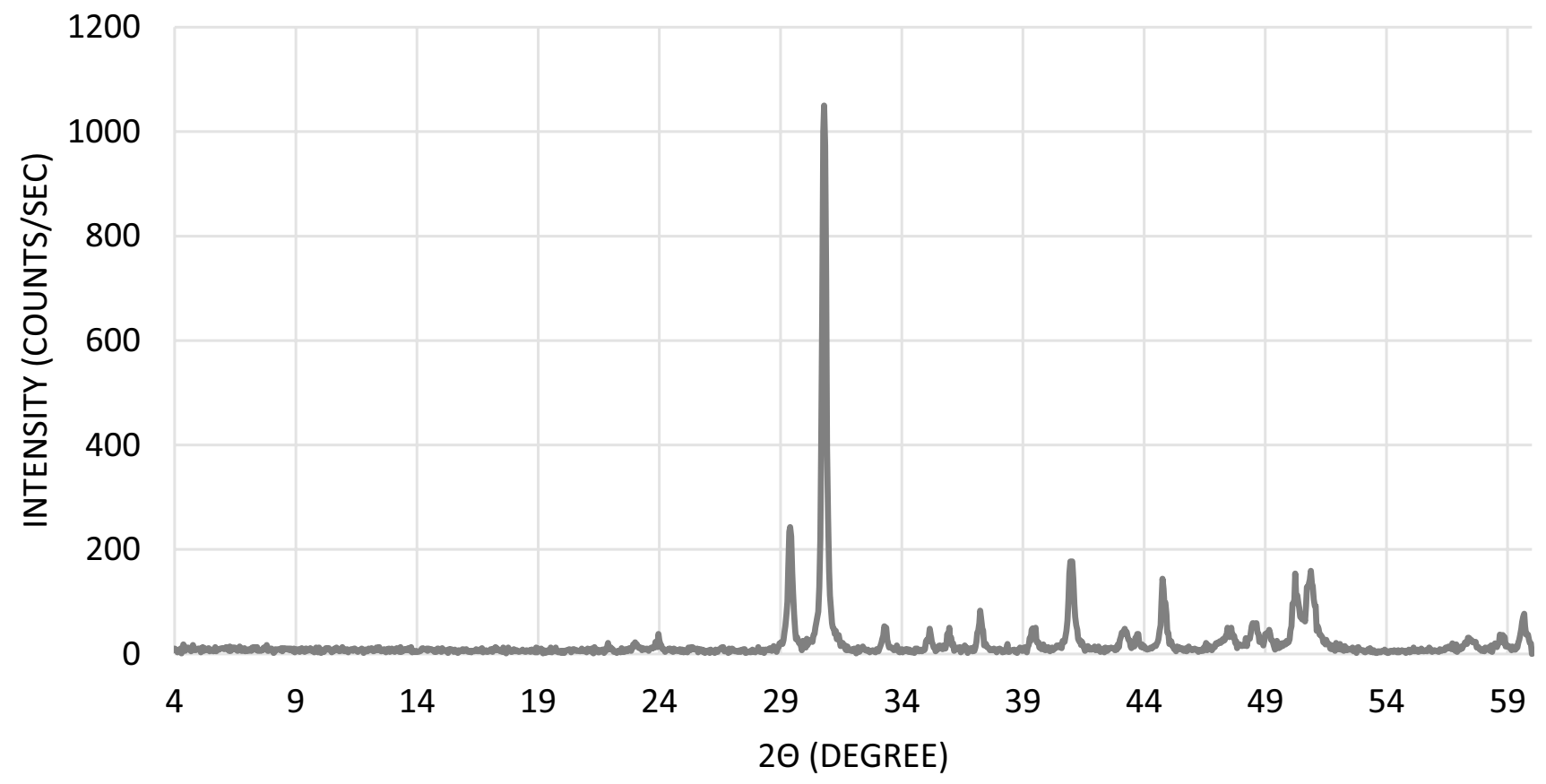

Fig. 1 XRD analysis of the rock sample (Core A) 


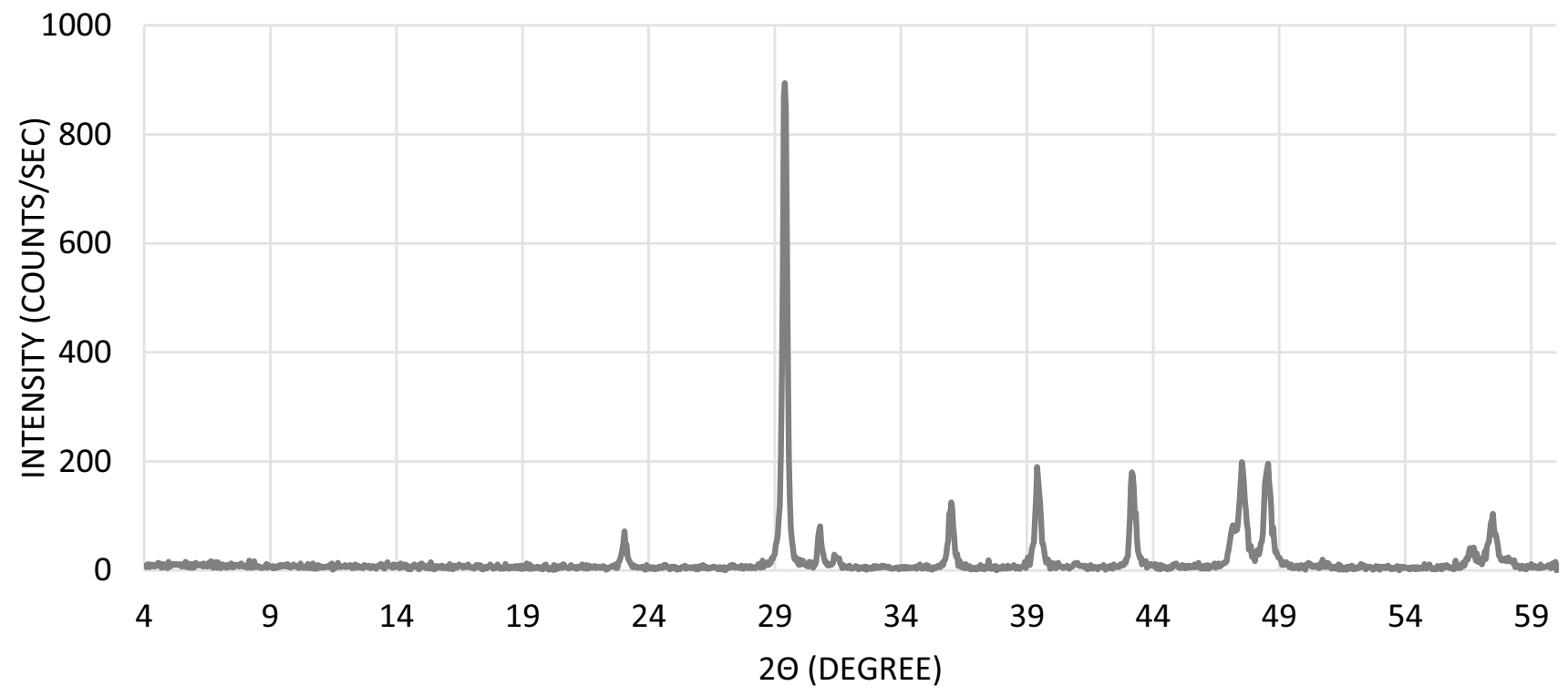

Fig. 2 XRD analysis of the rock sample (Core B)

Table 4 Crude oil composition

\begin{tabular}{ll}
\hline Component & Mole percent \\
\hline $\mathrm{H}_{2} \mathrm{~S}$ & 0.00 \\
$\mathrm{~N}_{2}$ & 0.00 \\
$\mathrm{CO}_{2}$ & 0.00 \\
$\mathrm{C}_{1}$ & 0.00 \\
$\mathrm{C}_{2}$ & 0.68 \\
$\mathrm{C}_{3}$ & 1.61 \\
$\mathrm{iC}_{4}$ & 0.61 \\
$\mathrm{nC}_{4}$ & 1.88 \\
$\mathrm{iC}_{5}$ & 0.84 \\
$\mathrm{nC}_{5}$ & 0.81 \\
$\mathrm{C}_{6}$ & 10.15 \\
$\mathrm{C}_{7}$ & 12.54 \\
$\mathrm{C}_{8}$ & 8.11 \\
$\mathrm{C}_{9}$ & 7.28 \\
$\mathrm{C}_{10}$ & 6.82 \\
$\mathrm{C}_{11}$ & 5.73 \\
$\mathrm{C}_{12}{ }^{+}$ & 42.94 \\
$\mathrm{Total}^{+}$ & 100 \\
$\mathrm{MWC}_{12}{ }^{+}$ & 454 \\
$\rho \mathrm{C}_{12}{ }^{+}$ & 0.9312 \\
\hline &
\end{tabular}

in distilled water, it is obvious that salts used for FW synthesize would be solved in deionized water. But for insurance, synthetic FW was filtered by a Whatman 42 filter paper, and some residue was seen. They were minor because of the impurity of salts. After making the synthesized FW, a $10 \mathrm{ml}$ sample was taken, and ion composition was re-checked. The results were similar to those given in Table 6. Deionized
Table 5 Physical properties of crude oil

\begin{tabular}{ll}
\hline Physical properties & Value \\
\hline Molecular wt. (g/mol) & 253 \\
Gravity ( $\left.{ }^{\circ} \mathrm{API}\right)$ & 26.35 \\
Density @ room temperature (gr/cc) & 0.8964 \\
Density @ reservoir temperature $(\mathrm{gr} / \mathrm{cc})$ & 0.8305 \\
Viscosity @ room temperature $(\mathrm{cp})$ & 23.7854 \\
Viscosity @ reservoir temperature $(\mathrm{cp})$ & 1.6473 \\
\hline
\end{tabular}

Table 6 FW and SW composition

\begin{tabular}{lrc}
\hline Ion & FW concentration $(\mathrm{mg} / \mathrm{l})$ & $\begin{array}{l}\text { SW concen- } \\
\text { tration }(\mathrm{mg} / \mathrm{l})\end{array}$ \\
\hline $\mathrm{Na}^{+} / \mathrm{K}^{+}$ & 75,198 & 16,958 \\
$\mathrm{Ca}^{2+}$ & 9600 & 533 \\
$\mathrm{Mg}^{2+}$ & 1458 & 1944 \\
$\mathrm{Fe}^{2+} / \mathrm{Fe}^{3+}$ & 0 & 360 \\
$\mathrm{CO}_{3}{ }^{2-}$ & 0 & 0 \\
$\mathrm{SO}_{4}{ }^{2-}$ & 550 & 4000 \\
$\mathrm{HCO}_{3}{ }^{-}$ & 488 & 105 \\
$\mathrm{Cl}^{-}$ & 136,675 & 28,400 \\
$\mathrm{TDS}^{-}$ & 223,969 & 51,400 \\
\hline
\end{tabular}

water and salts were mixed in the appropriate proportions. Normally $1 \mathrm{~L}$ of brine was mixed at a time. In this study, deionized water was used in experiments. Deionized water was taken from distilled water using Direct- ${ }^{\circledR}$ Water Purification System-EMD Millipore. 


\section{Effluent characterization}

\section{pH measurement}

pH was measured using a $\mathrm{HACH}$ pH meter on influx and effluent samples on ambient conditions. The sample was gently agitated until a steady reading was obtained. The meter was calibrated before each measurement with standard buffers of 4.01, 7.01, and $10.00 \mathrm{pHs}$.

\section{Ion analysis}

Core flood effluents were collected and divided into 4-5 parts. Each part was analyzed for possible ions exchange during the smart water wettability alteration process. The final results would give us a trend to discuss the mechanism of wettability alteration. All procedures were done according to international standards ASTM and SM (Fig. 3).

\section{Density and viscosity measurement}

The densities were measured by using a DMA 4500 Anton Paar Density Meter. The measurements were done by injecting $2 \mathrm{ml}$ of a sample into the density meter with a needle. The system needed to be free of any air bubbles. The density meter performed the measurement, and the value was given on the display. The viscosity of liquids is determined by an instrument called a viscometer.

\section{High-pressure/high-temperature IFT and contact angle measurement}

In this study, the captive drop instrument was used for measuring interfacial tension based on the pendant drop method. Surface tension and wettability at high pressures and temperatures conditions were up to 6000 psig and $200{ }^{\circ} \mathrm{C}$. All contact angle and IFT measurements are done in reservoir temperature. The schematic of the contact angle measurement device is shown in Fig. 4. In this test, Drop Shape

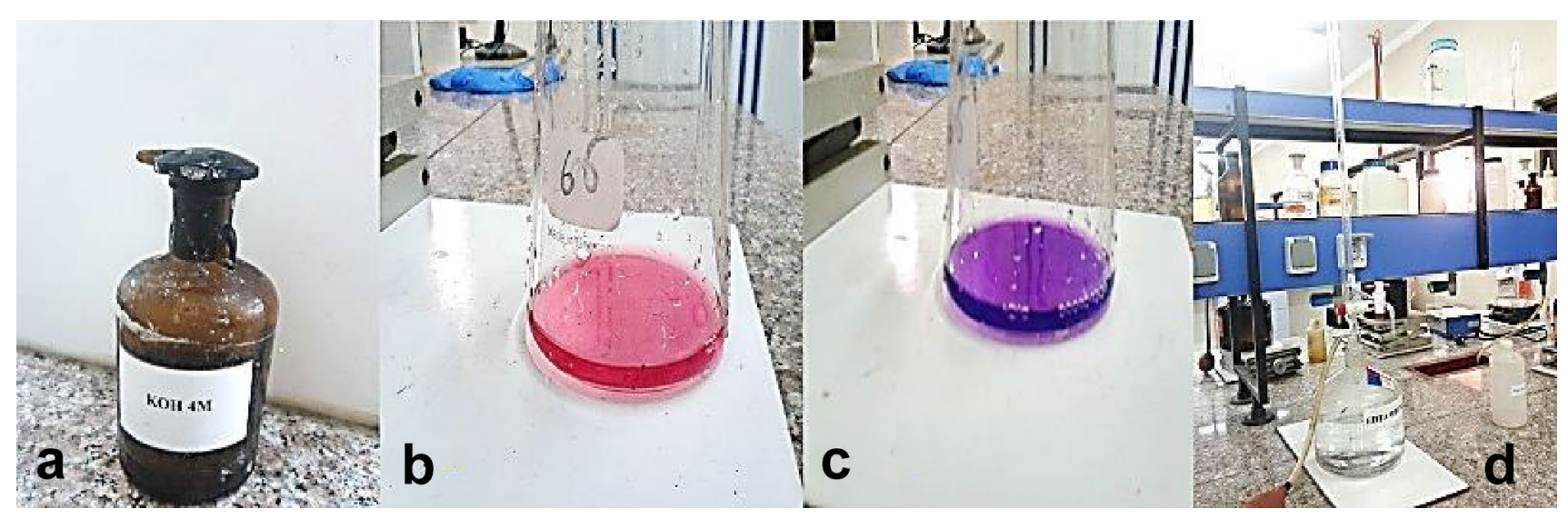

Fig. 3 Titration of magnesium ion. a KOH 4 M, b analyst after adding indicator, $\mathbf{c}$ analyst after titration with EDTA, d EDTA titration apparatus

Fig. 4 Schematic of the contact angle measurement device

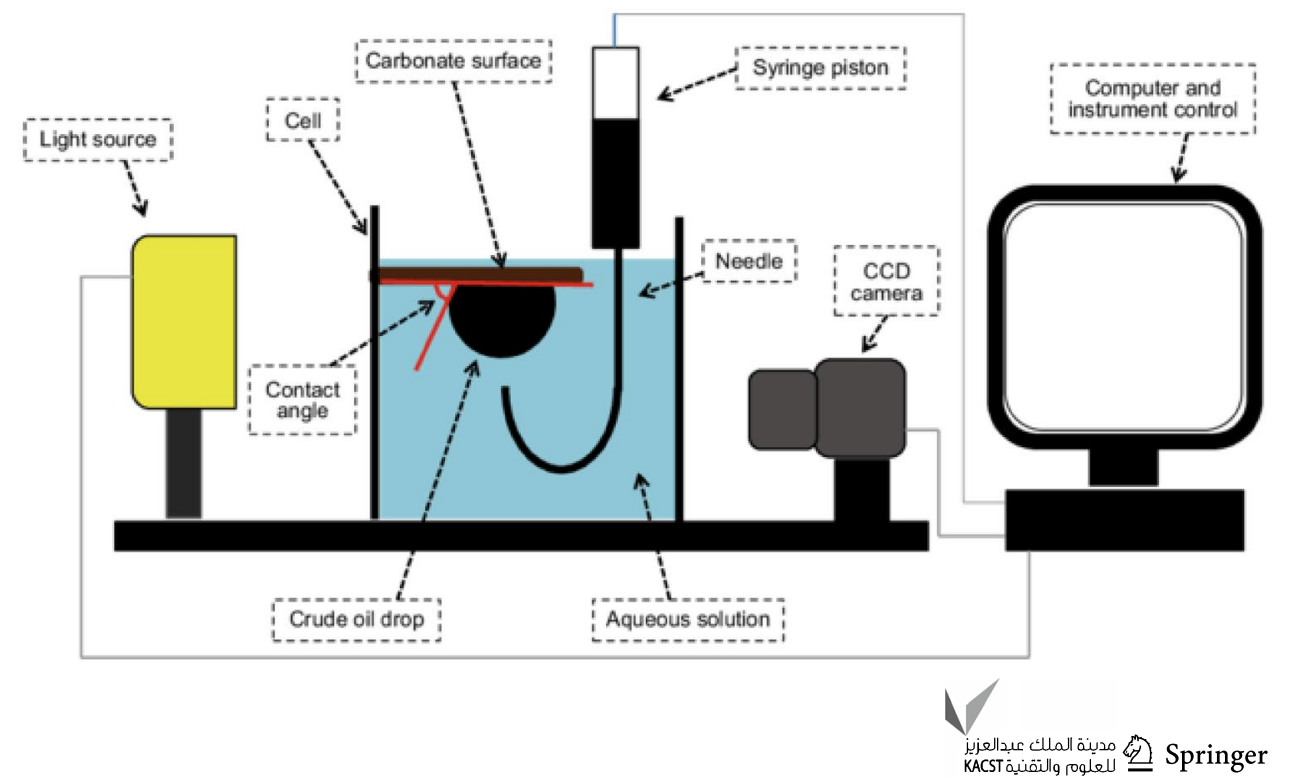


Analysis software named PDSA was used for axisymmetric drop shape analysis (ADSA) and geometrical method for drop shape analysis and IFT calculation.

\section{Experimental setup sequence and procedures}

\section{Setup sequence}

\section{- Cleaning of plug samples}

In this study, both Soxhlet and core flooding were used to clean samples because of the possibility of scale in pores. In the first step, each core plug was flooded by toluene (at least 10 pore volumes (P.V)) with a high rate of injection (1-2 $\mathrm{ml} /$ $\mathrm{min})$. Then, each core plug flooded by methanol same as toluene. In the following, each core was cleaned through a Soxhlet by toluene (at least 3 days) and methanol (at least 2 days), respectively.

\section{- Saturating sample using formation water}

After preparing and cleaning the core sample, it was placed in the rubber sleeve and put in the core holder. This sleeve was used as a connection in exert of overburden pressure, on the rock. In these experiments, the overburden pressure was provided by water (about $3500 \mathrm{psi}$ ). After placing each core plug in the core holder, plugs were vacuumed by using a vacuum pump for at least $4 \mathrm{~h}$. Then, the core plug will be saturated with formation brine by flooding. Flooding would continue until at least five-pore-volume formation water exists. Then, saturation with FW finished, but flooding at different rates continued to re-check water permeability of each plug. At last, porosity of plugs re-checks by weight difference.

\section{- Core flooding using crude oil saturation}

When uniform initial water saturation throughout the core was obtained, it was placed in a Hassler core holder in a heating chamber. The temperature in the chamber was set to reservoir temperature, i.e., $105{ }^{\circ} \mathrm{C}\left(221^{\circ} \mathrm{F}\right)$. After 3-4 h waiting (until temperature stabilization), core plugs are flooded with crude oil at a very slow rate (i.e., $0.1-0.15 \mathrm{cc} /$ $\min )$. The flooding process continued until $t$ no water production was seen. In the following, flooding continued again about $2-3$ pore volumes. The water output gathered, and initial water saturation of each core plug was calculated by weight difference. This process was repeated after each washing and saturation.

\section{- Aging of the core plugs}

By checking previous studies, it was decided to age each plug in formation water for at least 1 week at room temperature and crude oil for at least 1 month in reservoir temperature. So each core plug preparation consists of cleaning, saturation with formation water, aging with formation water for 1 week, saturation with crude oil in reservoir temperature, and aging with crude oil for 1 month.

\section{Water flooding procedure}

To investigate the effect of salinity, injection rates must remain constant and chosen such that they do not satisfy in Rapoport and Leas criterion of stabilization (Atthawutthisin 2012):

$L u \mu_{\mathrm{w}} \geq 1$

where $L$ is the core plug length $(\mathrm{cm}), u$ Darcy velocity of the fluid (cc/min), and $\mu_{\mathrm{w}}$ the viscosity of injection fluid (cp).

By substitution length of the core sample and viscosity of injected water in this criterion, it was concluded that the injection rate should be lower than $1.58 \mathrm{cc} / \mathrm{min}$ for core plug A and 1.47 for core plug B (at the worst condition with the highest viscosity). Accordingly, experiments with different water salinities were carried out at a constant injection rate $(0.25 \mathrm{cc} / \mathrm{min})$. This study consists of two steps, LowSal study and smart water. According to Austad et al. (2010), $5000 \mathrm{ppm}$ TDS is the first step of increasing recovery by LowSal (i.e., the upper limit of the LowSal). $5000 \mathrm{ppm}$ is an optimum salinity too economically. But further dilution can alter wettability more and consequently may result in a higher recovery (Hosseini et al. 2018). According to Souraki et al. (2018), injection of diluted water after higher-salinity water can enhance the recovery, and therefore, $2000 \mathrm{ppm}$ TDS was the next option.

\section{Low-salinity water effect on wettability alteration}

The core plugs flooded by FW were followed by diluted FW of TDS $=5000($ FW5000) and TDS $=2000($ FW2000). Next, SW and its diluted versions, TDS $=5000$ (SW5000) and TDS $=2000$ (SW2000), were used to flood the plugs. The third experiment was the injection of SW5000 followed by SW2000. Finally, in the fourth experiment, SW2000 was injected through each core plug followed by SW5000. The higher-salinity brine was injected at the end of the fourth step to check its effect. This injection configuration was not reported in the literature before. The summary of the first set of experiments is explained in Table 7.

Between every two experiments, core plugs were cleaned, saturated, and aged. A total of 20 core flood experiments 
Table 7 Summary of the first set of experiments

\begin{tabular}{llll}
\hline Experiment ID & $\begin{array}{l}\text { First injection (as secondary } \\
\text { recovery) }\end{array}$ & $\begin{array}{l}\text { Second injection (as tertiary } \\
\text { recovery) }\end{array}$ & $\begin{array}{l}\text { Third injection (as } \\
\text { tertiary recovery) }\end{array}$ \\
\hline EXP\#1 & FW & FW5000 & FW2000 \\
EXP\#2 & SW & SW5000 & SW2000 \\
EXP\#3 & SW5000 & SW2000 & - \\
EXP\#4 & SW2000 & SW5000 & - \\
\hline
\end{tabular}

Table 8 Ion concentration of smart water used in the second step $(\mathrm{mg} / \mathrm{l})$

\begin{tabular}{lrrrr}
\hline Ion & SW2000 & SW.0.5S & SW1S & SW2S \\
\hline $\mathrm{Na}^{+} / \mathrm{K}^{+}$ & 624 & 606 & 606 & 606 \\
$\mathrm{Ca}^{2+}$ & 20 & 20 & 20 & 20 \\
$\mathrm{Mg}^{2+}$ & 75 & 75 & 75 & 75 \\
$\mathrm{Fe}^{2+} / \mathrm{Fe}^{3+}$ & 14 & 0 & 0 & 0 \\
$\mathrm{CO}_{3}{ }^{2-}$ & 0 & 0 & 0 & 0 \\
$\mathrm{SO}_{4}{ }^{2-}$ & 155 & 78 & 155 & 311 \\
$\mathrm{HCO}_{3}{ }^{-}$ & 4 & 4 & 4 & 4 \\
$\mathrm{Cl}^{-}$ & 1105 & 1180 & 1151 & 1093 \\
$\mathrm{TDS}$ & 2000 & 1963 & 2011 & 2109 \\
\hline
\end{tabular}

were performed to measure wettability alteration by relative permeability change and recovery using each selected brine.

\section{Smart water effect on wettability alteration}

Earlier studies show that sulfate ion is one of the most important ones in smart water wettability alteration (Hosseini et al. 2018) due to its role to expel the carboxylate group from the surface rock. $\mathrm{SO}_{4}{ }^{2-}$ treats the surface by adding an excess charge even in carbonated rocks. To clarify the role of $\mathrm{SO}_{4}{ }^{2-}$ on the wettability alteration, sulfate ion was replaced by phosphate. Phosphate ion $\left(\mathrm{H}_{2} \mathrm{PO}_{4}{ }^{-}\right)$has similar electrostatic behavior with $\mathrm{SO}_{4}{ }^{2-}$. The best improvement in wettability alteration was observed in SW2000 flooding and therefore was selected for the smart water design. Removing sulfate from SW2000 was not trivial if deposit heating and barium chloride $\left(\mathrm{BaCl}_{2}\right)$ technique is used. Despite heating will change TDS (although can be reversed by diluting with DIW) and an unwanted large quantity of chloride will be introduced to the system. The excess chloride will have a great effect on the smart water performance and mechanism of action (Souraki et al. 2018). Three synthetic smart waters with the ion compositions near the SW2000 but different $\mathrm{H}_{2} \mathrm{PO}_{4}$ quantity were prepared: (1) The concentration of phosphate is half of the sulfate (SW.0.5S); (2) equal concentration (SW1S); and (3) twice the concentration (SW2S). Some minor changes in ion compositions were added to neutralize the electrical charge of brine by the changes in sodium or chloride (non-active ions). The final ion compositions are shown in Table 8.

A new set of core plugs were used for this experiment as previous ones (cut as close as possible) were damaged during step one. Table 9 summarizes the properties of core plugs used in the second step. Two types of smart water (phosphate cases) core flooding experiments were run. The selection was based on IFT and contact angle results which are discussed in the next section. 3.5-5 P.V brine is injected for all experiments (until no oil production was seen). Then, the rate of injection increased to $0.5 \mathrm{cc} / \mathrm{min}$ for another $1 \mathrm{P} . \mathrm{V}$ brine injection. Finally, the rate increased further to $1 \mathrm{cc} / \mathrm{min}$ 1 P.V more. These two extra injections ensure that no more oil will be produced by further injection.

\section{Results and discussion}

As was said before, this study consists of two sets of experiments. Each set would be discussed separately.

\section{Low-salinity water effect on wettability alteration}

\section{Recovery improvement}

As it is obvious in Figs. 5 and 6, SW2000 has the most recovery. It is due to the mechanism of multicomponent ionic exchange (MIE) and the double-layer effect. Throughout these two mechanisms if the salinity decreases, ions would separate and more space would be available for active anions and cations. Lowering salinity would increase diffuse
Table 9 Properties of core plugs used at the second step

\begin{tabular}{|c|c|c|c|c|c|c|}
\hline Core plug & Length (mm) & Diameter $(\mathrm{mm})$ & P.V (ml) & $\varnothing(\%)$ & $\begin{array}{l}\text { Water perme- } \\
\text { ability }(\mathrm{mD})\end{array}$ & $S_{\mathrm{wi}}(\%)$ \\
\hline AA & 49 & 37.05 & 9.19 & 17.39 & 6.16 & 26.11 \\
\hline BB & 56.2 & 36.99 & 8.77 & 14.50 & 0.317 & 28.50 \\
\hline
\end{tabular}


Fig. 5 Recovery factor versus P.V injected of core A at all four experiments
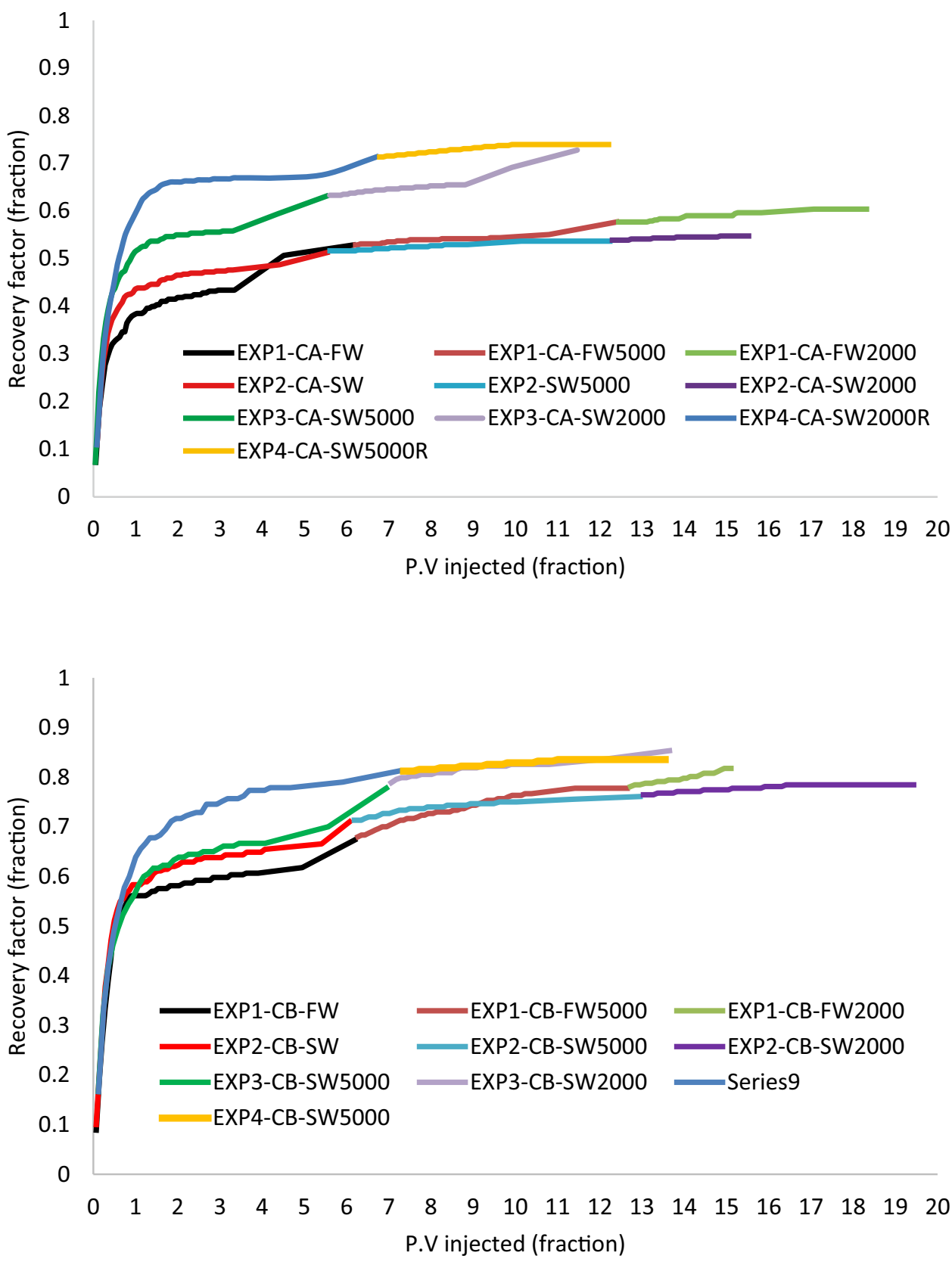

Fig. 6 Recovery factor versus P.V injected of core B at all four experiments of the rock tends to adsorb the magnesium group. So in outflow calcium concentration would increase, while magnesium and sulfate concentration generally would decrease (Hosseini et al. 2018).

As the work of Souraki et al. (2018) showed that dilution water increases recovery in each step, in this test increasing recovery was seen. Table 10 surmises the amount of oil recovery in each step. One of the most important points in Figs. 5 and 6 and Table 10 is that dilution of highersalinity water would increase recovery, but total recovery is less than the injection of LowSal directly water first injection. This point would be more important when the industry decided to use LowSal water. Maybe, the decision is to 
Table 10 Summary of recovery of first step core flood

\begin{tabular}{|c|c|c|c|c|}
\hline No. of experiments & Core plug & Water injection & Injection step & $\begin{array}{l}\text { Amount of } \\
\text { recovery }(\%)\end{array}$ \\
\hline \multirow[t]{3}{*}{ EXP\#1 } & \multirow[t]{3}{*}{ A } & FW & First injection & 52.88 \\
\hline & & FW5000 & Second injection & 4.81 \\
\hline & & FW2000 & Third injection & 2.70 \\
\hline \multirow[t]{3}{*}{ EXP\#1 } & \multirow[t]{3}{*}{ B } & FW & First injection & 67.33 \\
\hline & & FW5000 & Second injection & 10.44 \\
\hline & & FW2000 & Third injection & 4.00 \\
\hline \multirow[t]{3}{*}{ EXP\#2 } & \multirow[t]{3}{*}{ A } & SW & First injection & 51.27 \\
\hline & & SW5000 & Second injection & 2.40 \\
\hline & & SW2000 & Third injection & 1.10 \\
\hline \multirow[t]{3}{*}{ EXP\#2 } & \multirow[t]{3}{*}{ B } & SW & First injection & 71.00 \\
\hline & & SW5000 & Second injection & 5.11 \\
\hline & & SW2000 & Third injection & 2.33 \\
\hline \multirow[t]{2}{*}{ EXP\#3 } & \multirow[t]{2}{*}{ A } & SW5000 & First injection & 63.09 \\
\hline & & SW2000 & Second injection & 9.70 \\
\hline \multirow[t]{2}{*}{ EXP\#3 } & \multirow[t]{2}{*}{$\mathrm{B}$} & SW5000 & First injection & 77.77 \\
\hline & & SW2000 & Second injection & 7.55 \\
\hline \multirow[t]{2}{*}{ EXP\#4 } & \multirow[t]{2}{*}{ A } & SW2000 & First injection & 71.33 \\
\hline & & SW5000 & Second injection & 2.62 \\
\hline \multirow[t]{2}{*}{ EXP\#4 } & \multirow[t]{2}{*}{$\mathrm{B}$} & SW2000 & First injection & 81.22 \\
\hline & & SW5000 & Second injection & 2.33 \\
\hline
\end{tabular}

maintain pressure with SW or FW and then use smart water or LowSal water as tertiary recovery mode. In this experiment, it was shown that with equal P.V injection, LowSal water can have a better effect when used as the first injection instead of using after a high-salinity brine. The other point is at using higher-salinity brine after the lower one. It was investigated at EXP\#4. Using higher-salinity water after a lower one can increase ionic concentration at the surface and decrease diffuse layer thickness. Another effect is the reduction in the exchange density of active ions because of the presence of non-active ions. It would cause a reduction in active ion interactions, but surely interactions would continue and separation of carboxylate group will not stop. It is the reason for recovery in the case of SW5000 at EXP\#4. It would be expected that with higher salinity than $5000 \mathrm{ppm}$, recovery continued. Unfortunately, for a matter of time, it was impossible to investigate higher-salinity water after SW5000. But with these observations doing a batch flow of LowSal water followed by higher-salinity water can improve recovery and wettability alteration more than using a LowSal after high-salinity water. The reason can be because of the existence of non-active ions (from high-salinity water) that affect diffuse layer thickness and exchange density of active ions. Finally, it is obvious from Figs. 5 and 6 that core B had more recovery. It is because of the pore size distribution of core B in comparison with core A. The lower permeability of core B cannot be the reason at all. So it is obvious that the comparison of two core floods with two different core is not a proper reason to explain wettability alteration. But because in this project every work had done on the same plug, comparison can be rational.

\section{Relative permeability change}

Relative permeability calculations are done by Sendra analysis. Sendra is a two-phase 1D black-oil simulation model used for analyzing single SCAL experiments as well as several SCAL experiments simultaneously. It is tailor-made for revealing relative permeability and capillary pressure from two-phase and multi-phase flow experiments performed in the SCAL laboratory. Sendra covers oil-water, oil-gas as well as water-gas experiments, and both imbibition and drainage are handled. A third stagnant phase can easily be included. In Sendra, there are six different correlations for relative permeability calculations. The advantage of Sendra compared to other methods is the history matching process and user-friendly graphical interface. In this method, the well-known Corey's relative permeability correlation is used to analyze data to get relative permeability curves. Here is the result of the Sendra analysis software.

Three types of permeability can be used for base permeability and to calculate relative permeability: absolute permeability, oil permeability at residual water saturation (for oil-wet rocks), and water permeability at residual oil saturation (for water-wet rocks). Because core plugs are carbonate and naturally oil-wet (this is approved by contact

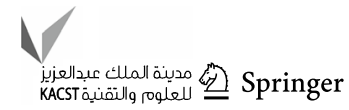


angle measurement), and because of enough aging time for wettability alteration, oil permeability at residual water saturation was picked to plot relative permeability curves. $S_{\mathrm{o}}$ $K_{\text {ro }}\left(S_{\text {wi }}\right)=1$ (Figs. 7 and 8). In this study, SW is selected as a base case to compare results to each other (because SW used commonly on pressure maintenance). As it is obvious in Figs. 7 and 8, the most wettability alteration is done by SW2000. It was anticipated as a result of the recovery in the last section. The remarkable point of this section is the difference between relative permeability curves by using each brine. As previous works showed (Souraki et al. 2018), dilution of brines can tend to more wettability alteration. This was approved in the last section as a result of injection lower salinity brine after a higher one. But in the case of relative permeability, it is obvious that SW and FW are too near to each other. In the case of core plug A, the point of crossover of relative water permeability by relative oil permeability is even higher than SW. In core plug B, this point is lower than SW. But in fact, both are so close to SW to even distinguish them. So as a result, it can be said that for the condition used in this project, using FW and SW can have the same results. The reason for this phenomenon is at the TDS of two brines. Both of them had a high TDS, and TDS is too effective for smart water wettability altering mechanism.

\section{The possible effect of inter facial tension (IFT) on recovery and relative permeability}

The relation between smart water and IFT is somehow unclear. Some researchers tried to investigate this subject, but sometimes the relationship between each ion in smart water and IFT has not a logical trend (Hosseini et al. 2018). A flooding process is affected by two mechanisms to EOR: wettability alteration and IFT reduction. A simple core flooding process is influenced by both simultaneously, i.e., even when there is not any aging time, flooding can differ the wettability (but it is so minor and negligible). The second mechanism is the IFT reduction. Any change
Fig. 7 Relative permeability curves of core $\mathrm{A}$, the difference between four experiments
Fig. 8 Relative permeability curves of core A, the difference between four experiments
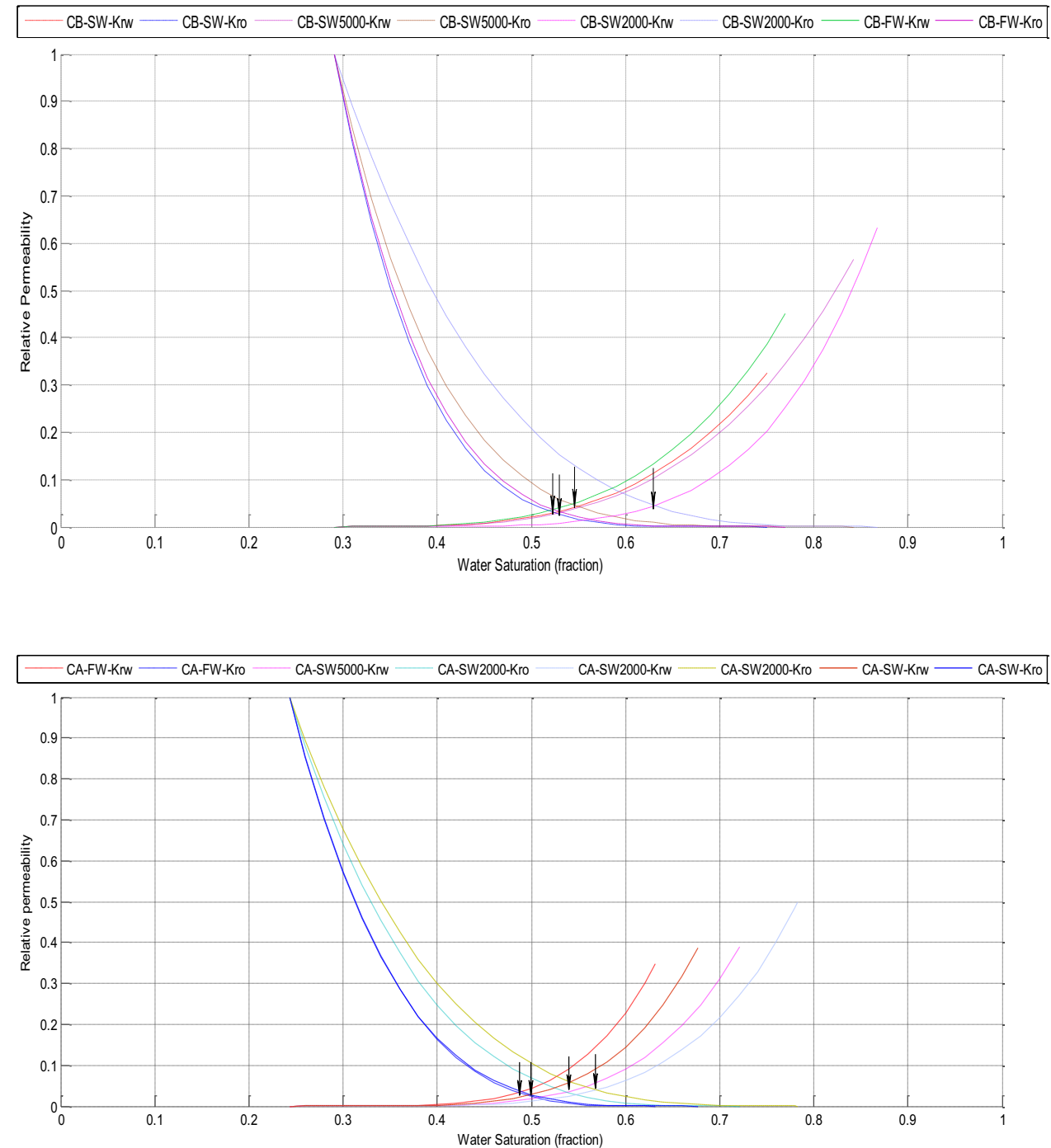
in water composition (even ionic or not) can alter IFT. So it is so important to have a look at IFT change in each recovery process.

Figure 9 shows IFT alteration during the use of each brine. All IFT tests are done in reservoir temperature $\left(105{ }^{\circ} \mathrm{C}\right)$. The pressure has remained at room condition. It was because IFT alteration with pressure is negligible in dead filtered oil (Hosseini et al. 2018). The mechanism of IFT reduction by smart water is somehow explained by Austad et al. (2010). In this mechanism, the carboxyl group's nonpolar head would face the oil droplet and the polar head would face the water phase. Polar head has a negative sign charge that tends to adsorb cations. So similar to the MIE mechanism, in high temperature $\left(>70{ }^{\circ} \mathrm{C}\right)$ calcium ions and in low temperature $\left(<70{ }^{\circ} \mathrm{C}\right)$ magnesium ions would adsorb to the polar head. Anions such as sulfate and chloride act as a layer of ions that can disturb the surface. With lower salinity of anions, it is rational that cations can adsorb more to the carboxyl group because of freedom of anions. All ions are in the aqua phase and covered with water molecules. So with adsorption of cations, water would be near to the oil phase and IFT reduces. But it would not continue in all dilutions of LowSal brine. It is obvious in Fig. 9 that in 2000 ppm brines IFT increased. It is because of a reduction in cations. So dilution cannot always reduce IFT. There is an optimum salinity of cations to optimize the reduction in IFT, and in this project, it seems to be $5000 \mathrm{ppm}$. Of course, it is not optimum, but in this project, between these brines, $5000 \mathrm{ppm}$ TDS is an optimum salinity for cations to react and reduce IFT. The proposed mechanism is illustrated in Fig. 10.

Increasing IFT at $2000 \mathrm{ppm}$ TDS brine confirmed that increasing recovery of $2000 \mathrm{ppm}$ TDS is more dependent on wettability alteration (instead of IFT reduction) in contrast with $5000 \mathrm{ppm}$ TDS.

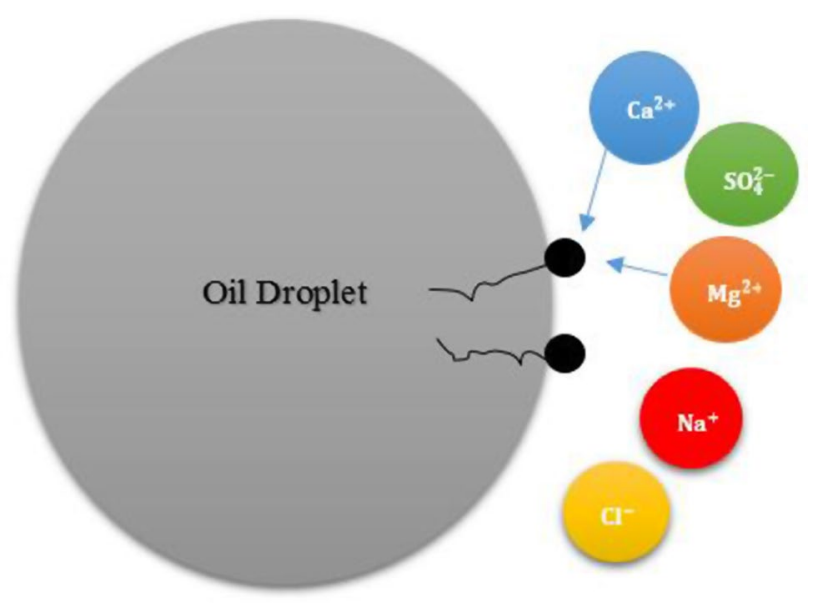

Fig. 10 Schematic of the effect of ions in IFT

\section{Contact angle change}

Contact angle measurement is a way to discuss wettability alteration by value (quantity). As it was said before, contact angle measurements had been done in reservoir temperature. This was because of the effect of magnesium ions in temperature greater than $70{ }^{\circ} \mathrm{C}$ (Souraki et al. 2018). After doing the test, the results are as shown in Fig. 11.

As it is obvious, FW and its dilutions had a low wettability alteration. This phenomenon could be because of natural surfactant in SW, but this theory could not be accepted (take a look at second step experiments). Using synthetic SW instead of SW showed a lower wettability alteration, but FW showed minimum wettability alteration. In the smart water wettability alteration process, there are not just ions that could affect wettability alteration. The concentration of each ion comparing to the other one is important too, and some researchers believe that SW could be even the
Fig. 9 IFT of different waters used

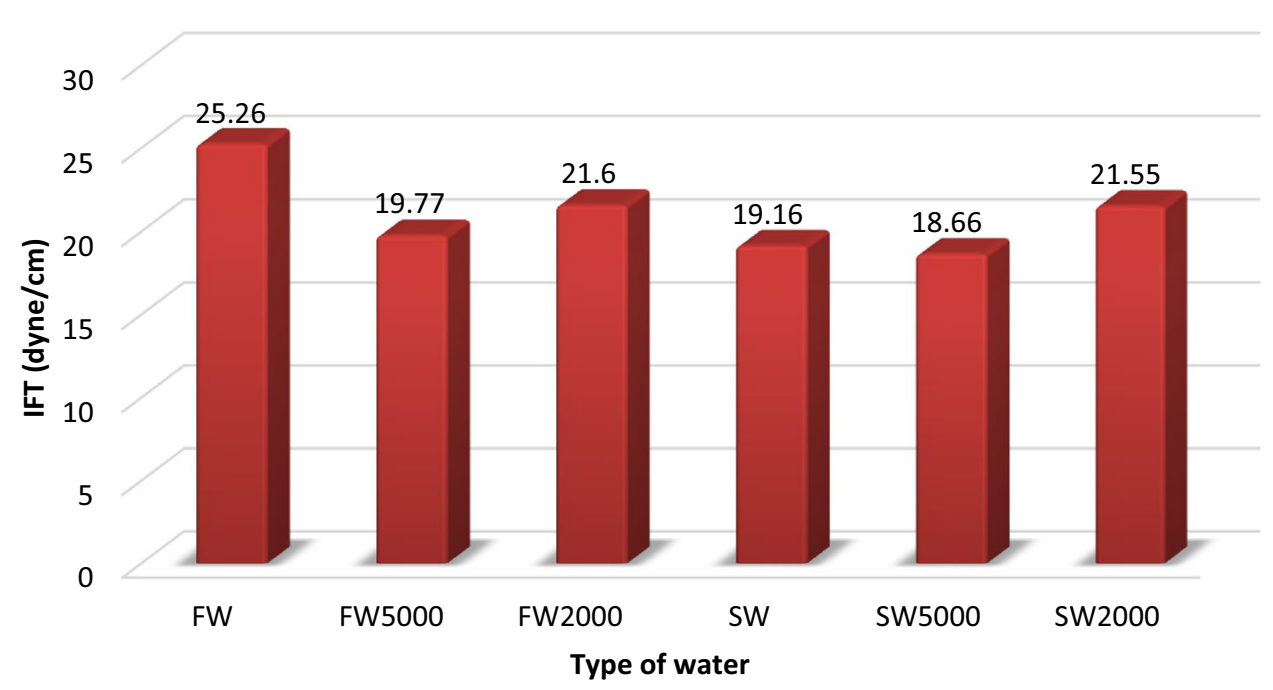

Type of water

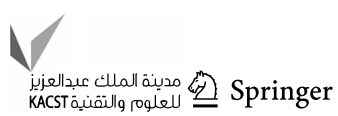


Fig. 11 Contact angle change through using different brine

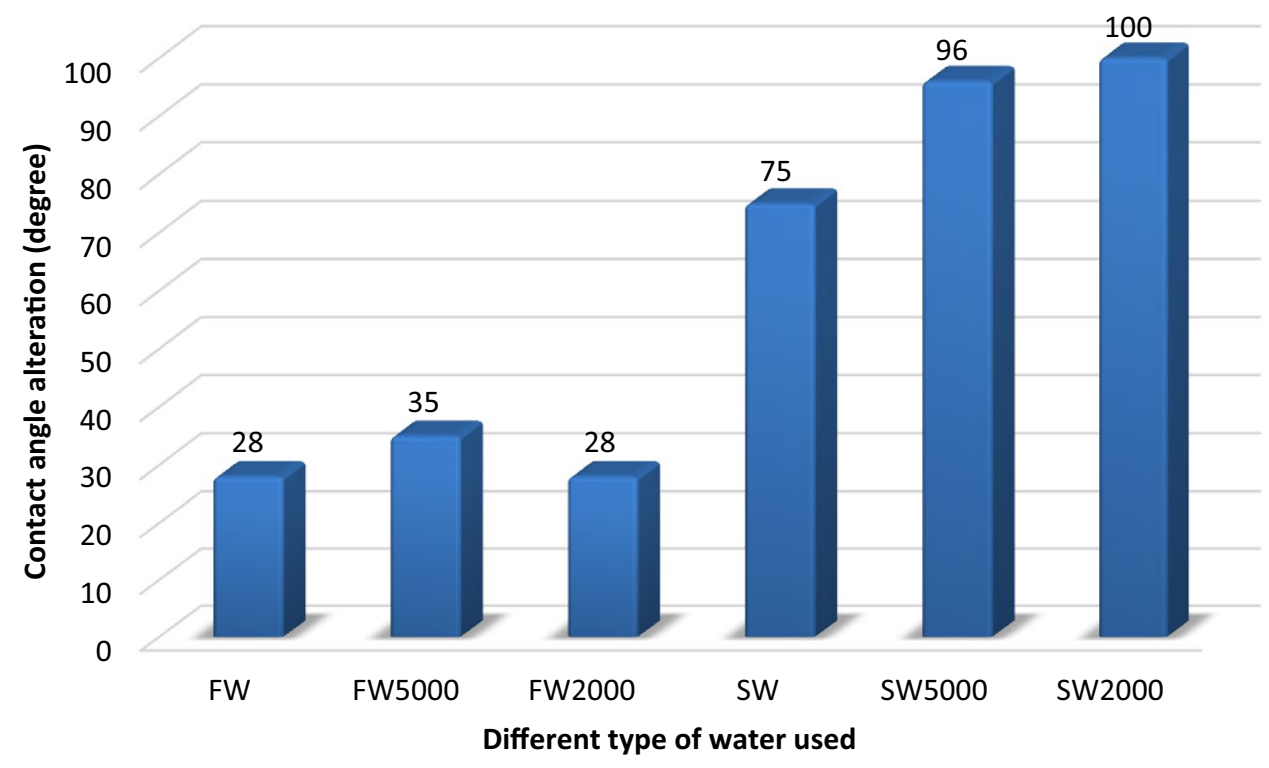

optimum ion concentration (Souraki et al. 2018). Now, it may be a question that why the flooding process and relative permeability curves did not show this difference too. The answer could be in capillary pressure, swipe efficiency effects, and running a dynamic test instead of a static one. The low effect of smart water wettability alteration could happen in higher-salinity brines (such as SW and FW). But in high-salinity brines, the ratio between ion concentrations is still an important matter.

\section{Outflow analysis}

After gathering the outflow of the core flooding experiment, outflows are divided into four samples to analyze. At first, $\mathrm{pH}$ of outflows had been analyzed.
pH As we know, pH increasing is a result of the smart water wettability change mechanism (Hosseini et al. 2018). In this study, outflow $\mathrm{pH}$ is measured to see how the change of this parameter is. The following figures show the result of changing $\mathrm{pH}$ (Figs. 12, 13, 14, 15).

$\mathrm{pH}$ increasing was seen in all experiments in the first step. The amount of increase is in the range of 0.1-2. Every output (except FW) pH stabilized at 7.5 or 8 . This stabilization is through carbonate dissolution. Through these chemical reactions, carbonate dissolved, calcium and hydroxide released, and $\mathrm{pH}$ increased. This process would be in equilibrium after a while, and $\mathrm{pH}$ would be stabilized. Another reason for increasing $\mathrm{pH}$ is that with MIE and double-layer wettability alteration mechanisms, calcium and magnesium would be used to alternate wettability. The amount
Fig. $12 \mathrm{pH}$ difference of EXP\#1 (FW and its dilutions flooding)

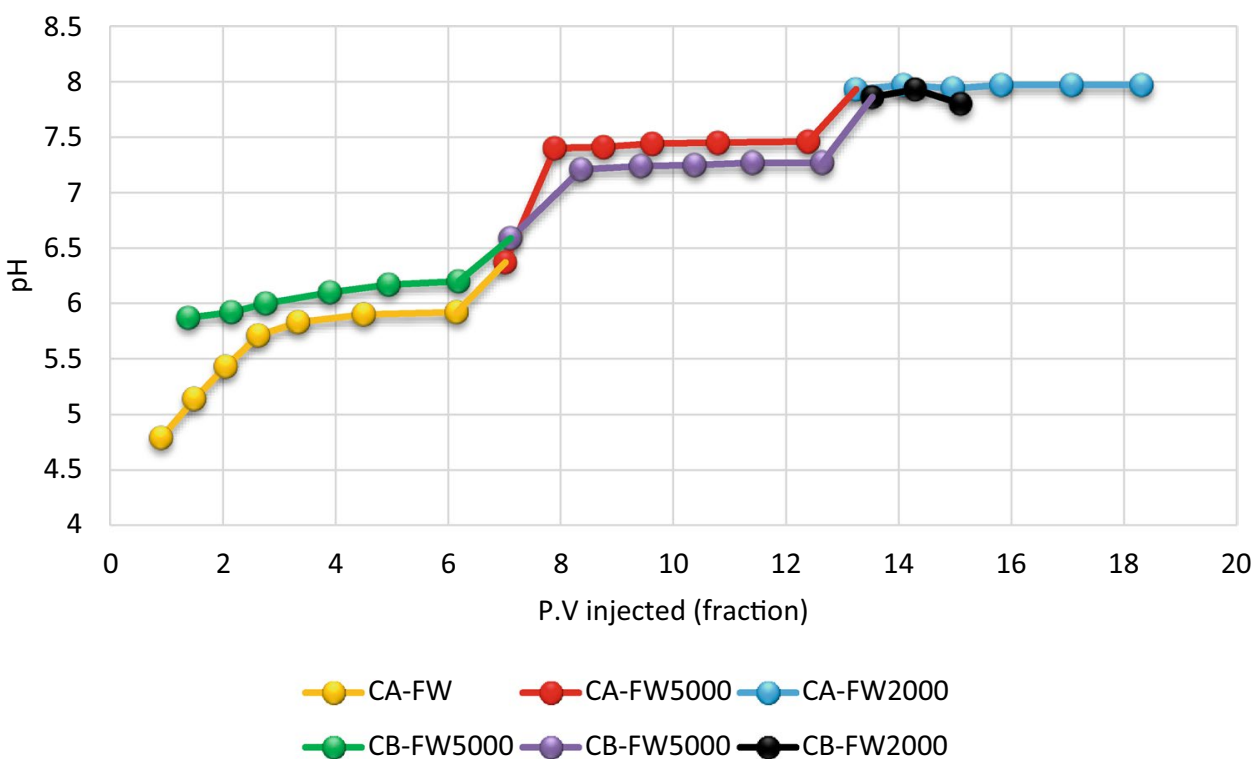


Fig. 13 pH difference of EXP\#2 (SW and its dilutions flooding)

Fig. 14 pH difference of EXP\#3 (SW5000 and its dilution flooding)

Fig. $15 \mathrm{pH}$ difference of EXP\#4 (SW2000 and its higher salinity SW5000)

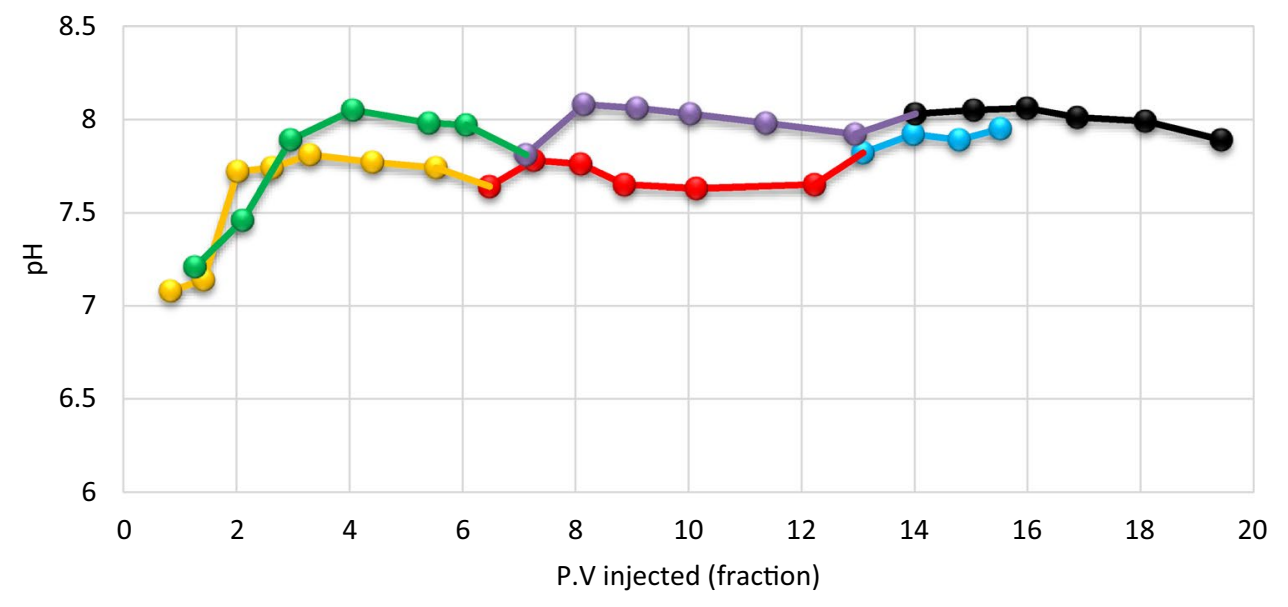

- CA-SW -CA-SW5000 -C-CA-SW2000 -CB-SW -CB-SW5000 -CB-SW2000

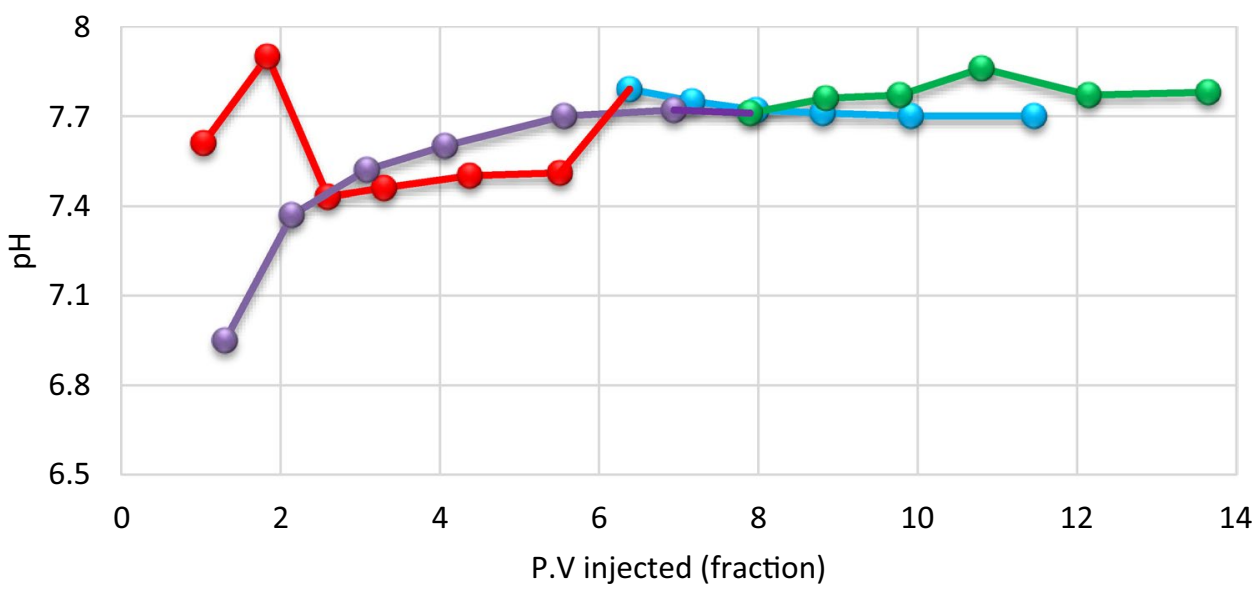

-CA-SW5000 -CA-SW2000 -CB-SW5000 -CB-SW2000
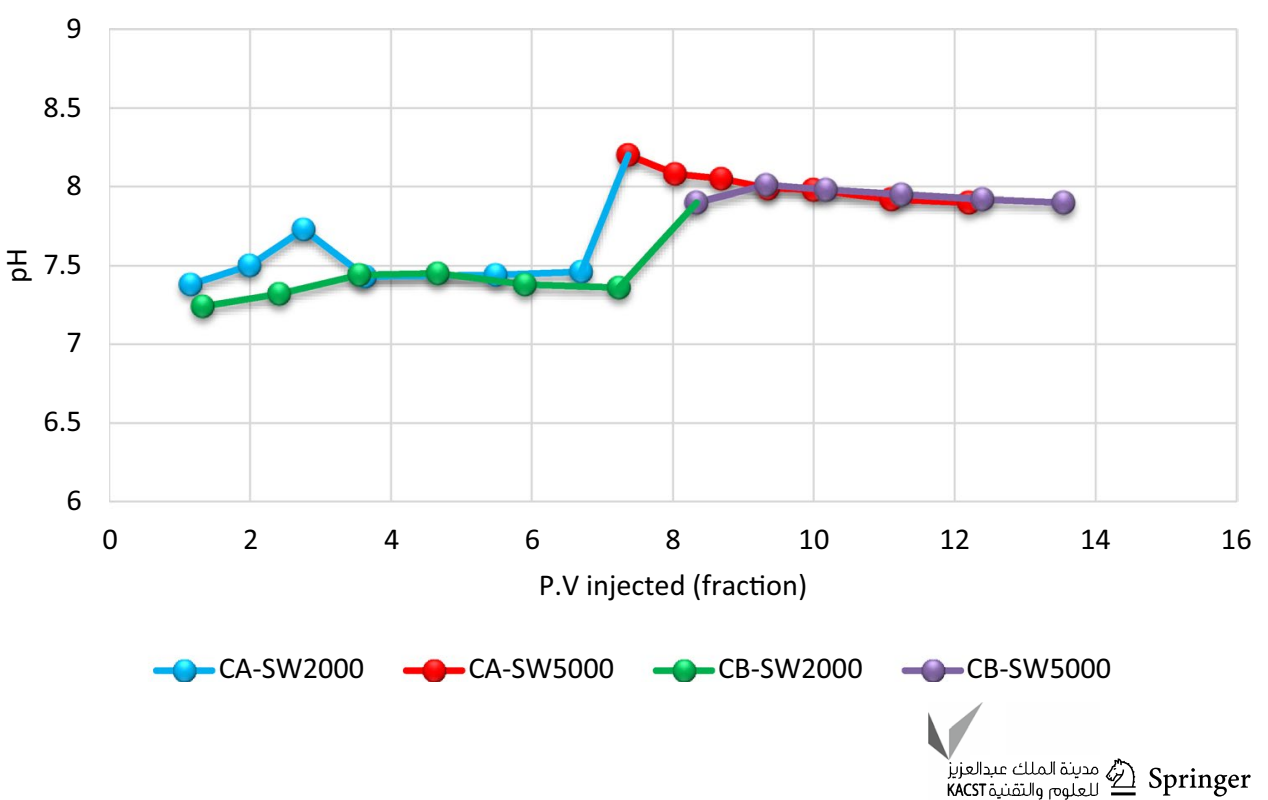
of calcium and magnesium consumption from the diffuse layer would compensate by the consumption of sodium and hydrogen cations (as shown in outflow ion analysis results). It would cause hydroxide release and increase $\mathrm{pH}$.

Ion analysis After six P.V injections, injection brine changed to a diluted one. Because dilution was in a high ratio (about $1 / 10$ to $1 / 44$ ), it is obvious that outflow would have a great number of ions after changing the injection brine. Because of this matter, vertical access to Fig. 16 is set to $0-4$. Practically, amount upper than four was too high to show. Magnesium and sulfate were ions that had much more concentration in outflow in proportion to others. Figure 17 shows the real amount of concentration change in
Fig. 16. In the following tables, $C / C 0$ is the concentration ratio between outflow ()$^{\circ}$ and inflow $(C 0)$ of each ion.

Because of the repeatability of all experiments in the first set, easily the trend in Figs. 16, 17 can be re-checked for core B in Figs. 18 and 19.

By noticing on MIE and double-layer mechanisms, it was desired to have more calcium and less magnesium and sulfate in the outflow. In the above figures, higher calcium concentration is proved $(C / C 0>1)$, but the outflow of sulfate ion is too much from the beginning, and after a while, it is reducing. It can be explained by the capacity of the rock surface. Surely, rock surfaces cannot absorb as much ion as available in injection water. Another explanation is the exchange density of sulfate. The exchange density of sulfate is low when other non-active ions are available.
Fig. 16 EXP\#1 core A outflow analysis

Fig. 17 EXP\#1 core A outflow analysis (original scale)
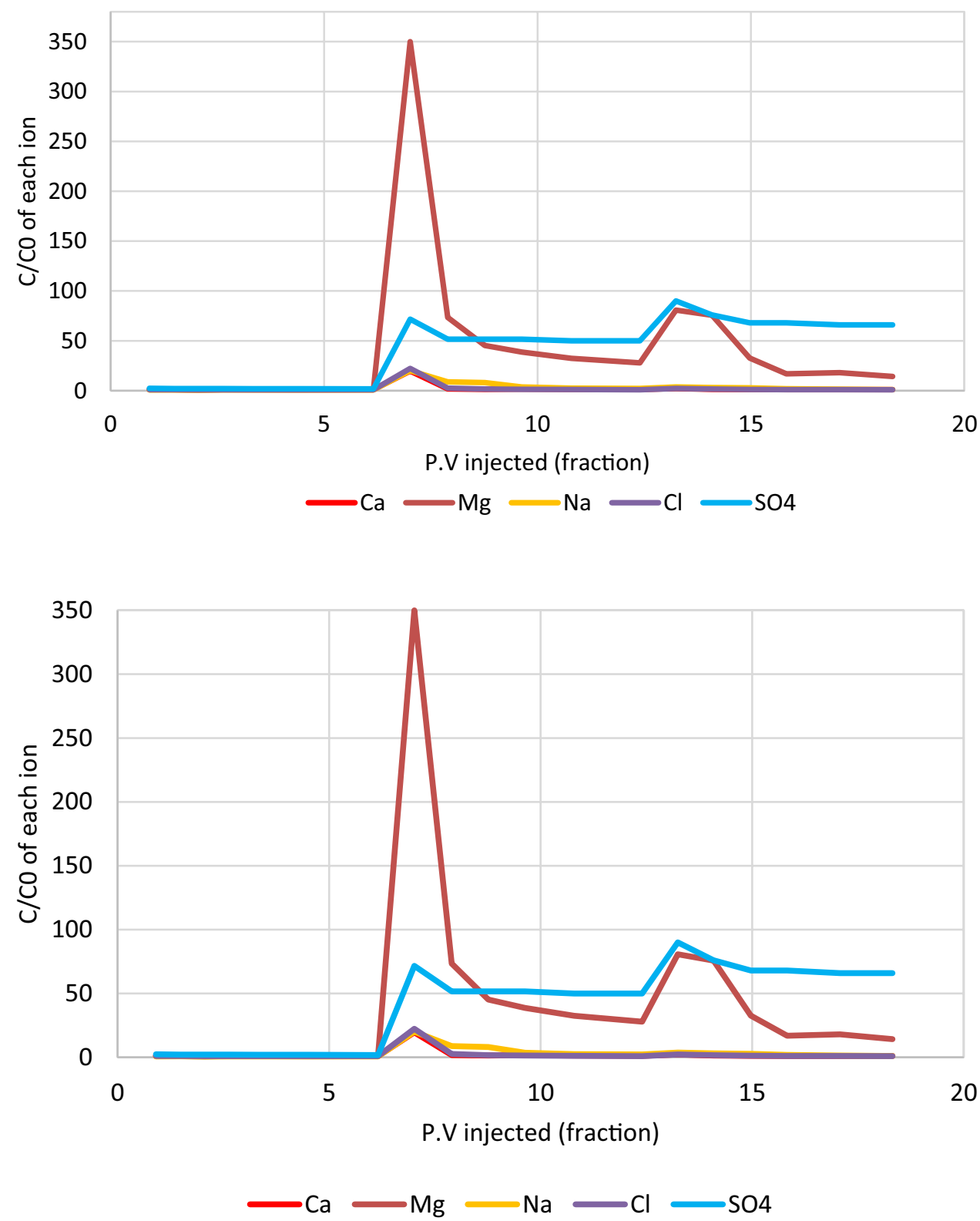
Fig. 18 EXP\#1 core B outflow analysis
Fig. 19 EXP\#1 core B outflow analysis (original scale)
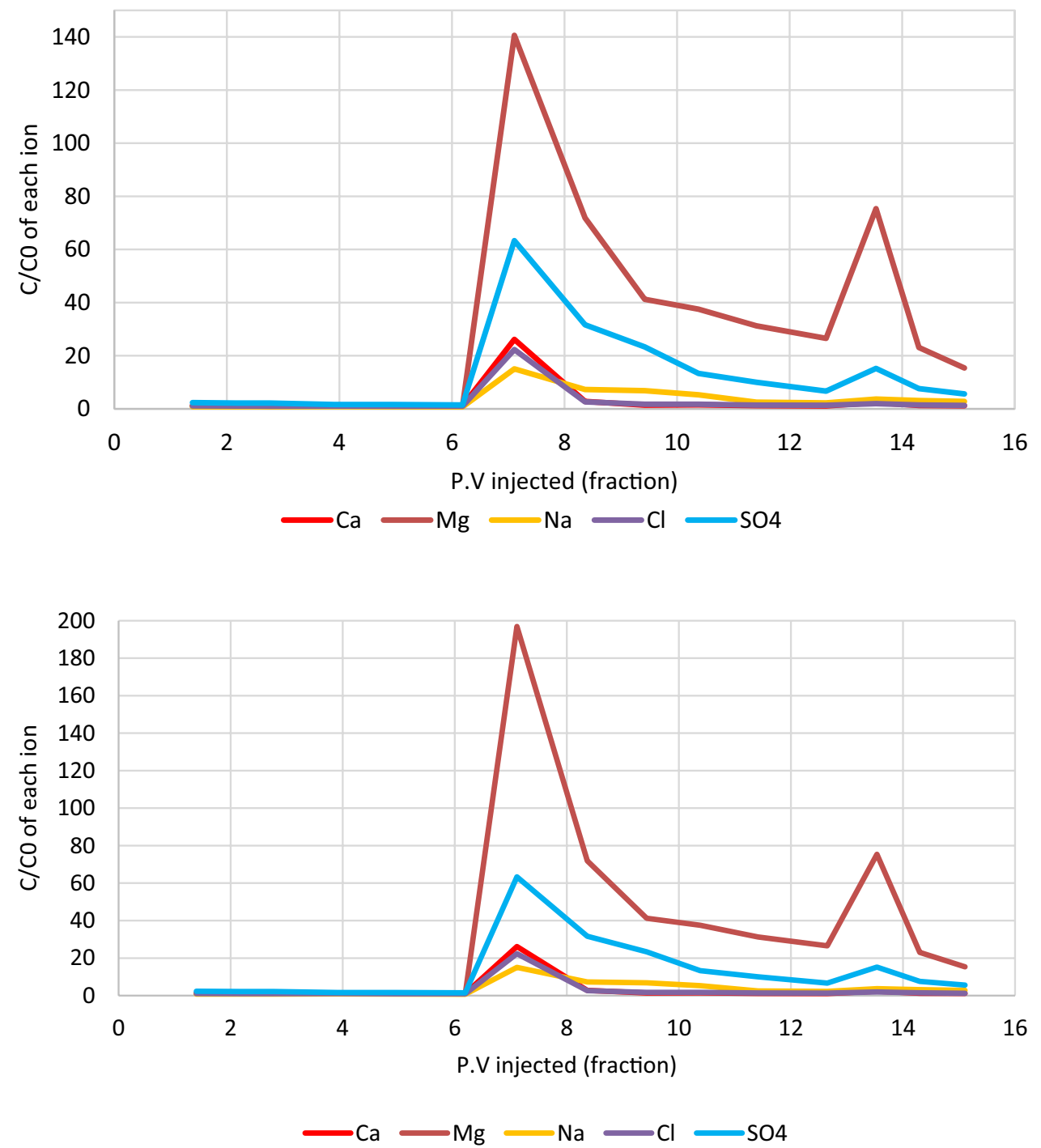

Non-active ion concentration would affect the diffuse layer and decrease the exchange density of sulfate. As it is obvious from Figs. 18 and 19, sulfate concentration is high at the start of flooding but reduces after a while. FW cannot change wettability too much. Considering contact angle results, the reason could be the high amount of TDS and non-active ion concentration. The excess amount of each ion would be flowed out by the flooding process. Magnesium produced a little and consumed again at the start of flooding with FW. It is negligible in contrast with sulfate and would be stabilized after a while. But in the second flooding process production of magnesium would be too much in contrast with LowSal FW5000. Other ions would be produced too, but their production is due to a logical pattern and tends to stabilize. The reason could be because of decreasing magnesium concentration in the diffuse layer after injection of FW5000 and FW2000. Magnesium ions that are attached to the surface would meet new exchange density in the diffuse layer, so they would be separated from the surface and produced in a high concentration. Magnesium behavior was seen, while the calcium outflow trend confirmed the mechanism said before; this is due to less absorption of calcium ions to the surface at a temperature greater than $70^{\circ} \mathrm{C}$. Sodium ion was produced less than entrance concentration. It was weird. It seemed that with producing calcium ion, sodium consumed and compensated the lake of a positive ion. It is so important and can approve that even the presence of sodium ion is crucial (while sodium is not an active ion) and can have a great effect on the mechanism of wettability alteration. As it was expressed in the $\mathrm{pH}$ alteration mechanism, the consumption of sodium and hydrogen would cause $\mathrm{pH}$ increasing. The difference between the trend of magnesium consuming in core A and B is because of reservoir rock material investigated by the XRD test. Core A has more dolomite than core B (Figs. 20, 21, 22, 23).

In EXP\#2, SW and its dilutions are used as injection brine. By looking at the trend of changing ions, magnesium produced and consumed a little at first. In the second and

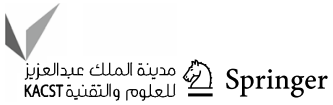


Fig. 20 EXP\#2 core A outflow analysis

Fig. 21 EXP\#2 core A outflow analysis (original scale)

Fig. 22 EXP\#2 core B outflow analysis

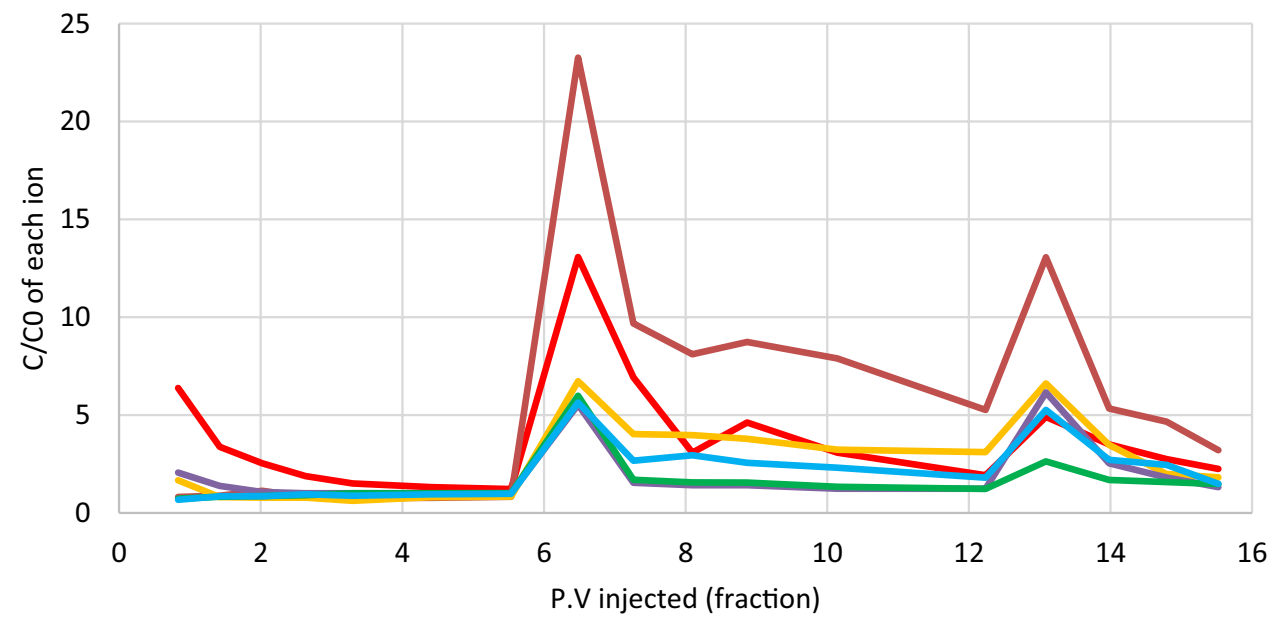

$\longrightarrow \mathrm{Ca} \longrightarrow \mathrm{Mg} \longrightarrow \mathrm{Na}=\mathrm{Cl} \longrightarrow \mathrm{K}=\mathrm{SO} 4$

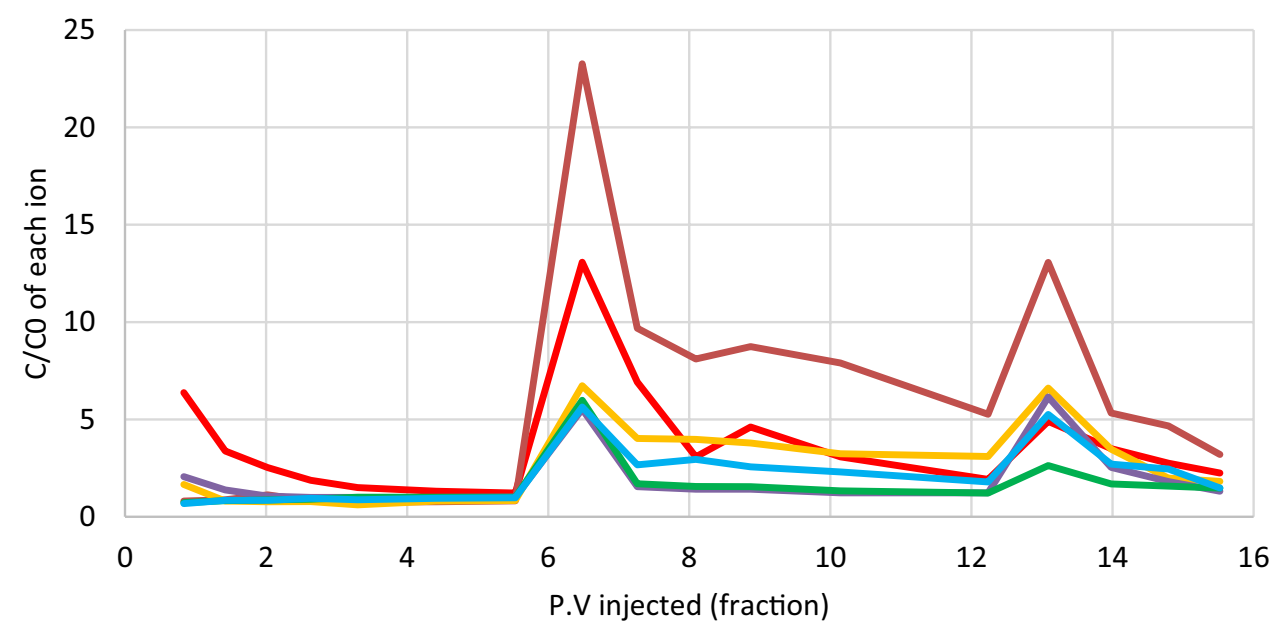

$\longrightarrow \mathrm{Ca} \longrightarrow \mathrm{Mg} \longrightarrow \mathrm{Na} \longrightarrow \mathrm{Cl} \longrightarrow \mathrm{KO}$
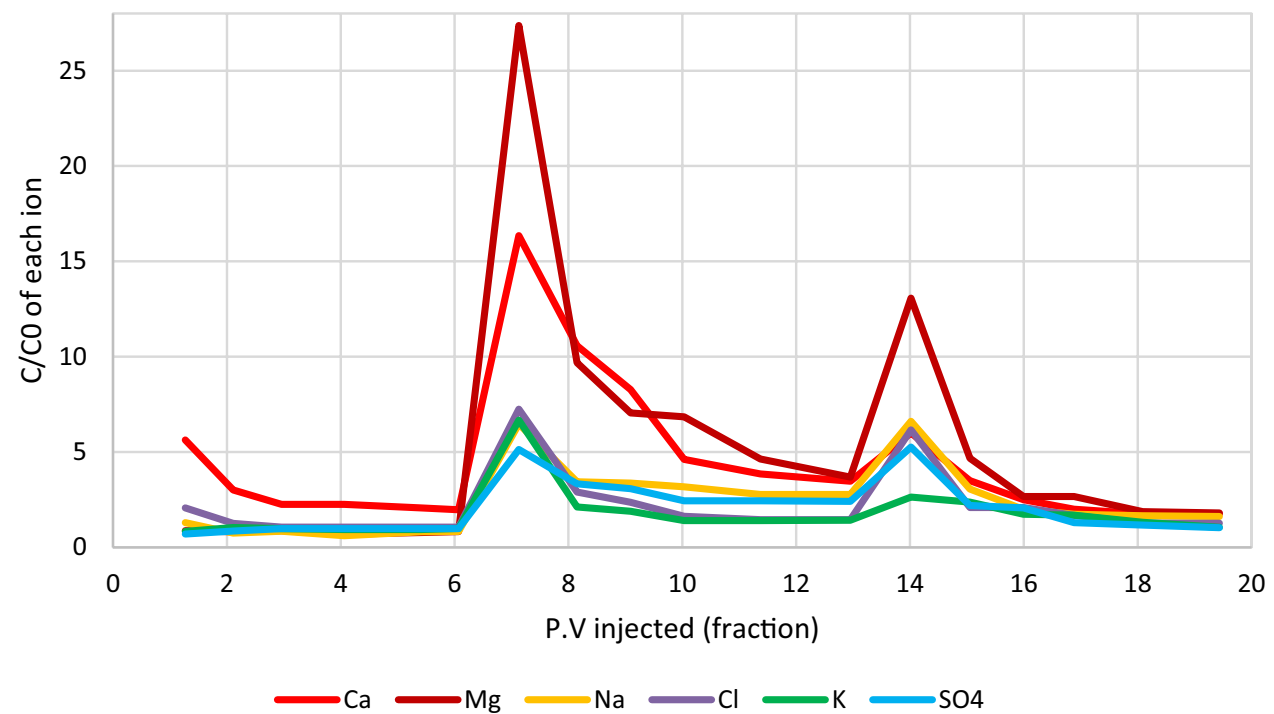
Fig. 23 EXP\#2 core B outflow analysis (original scale)

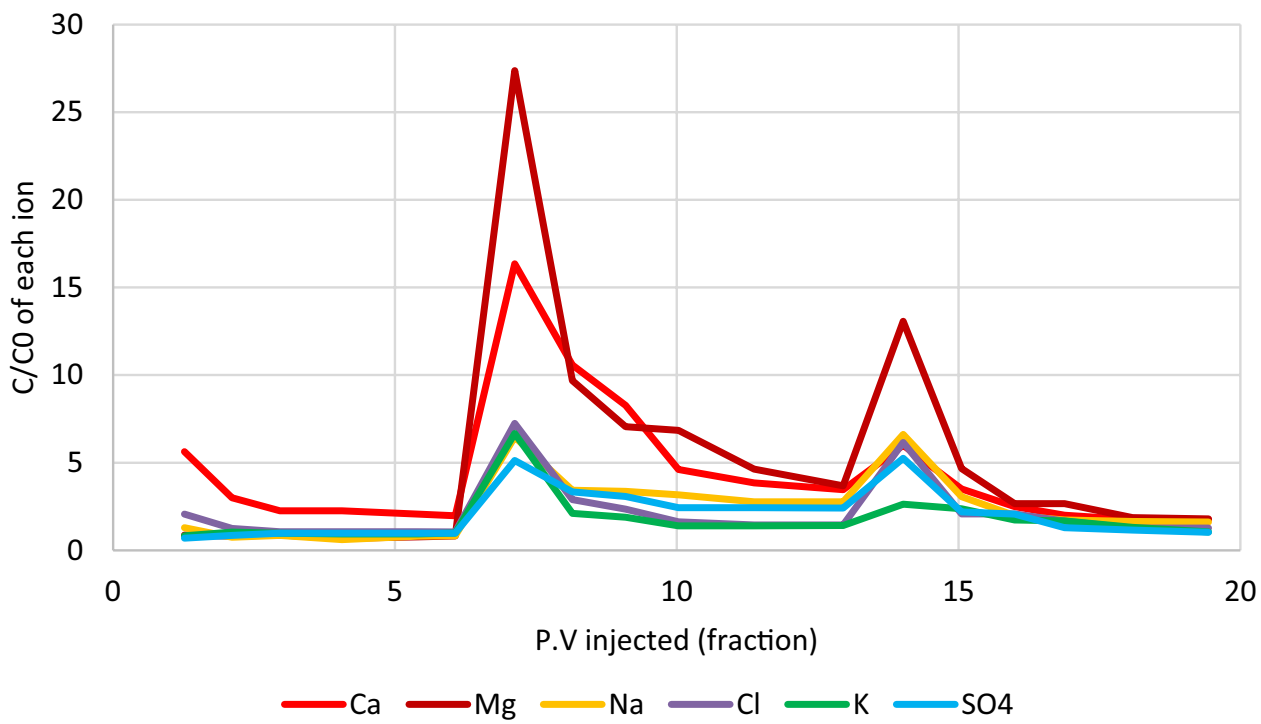

third flooding, magnesium produced a lot (same as FW). Sodium ion consumed and produced is just like the FW case. The reason and mechanism are the same as the FW case and approved the previous discussion. There are two new points in SW outflows: (1) producing some amount of chloride; (2) logical behavior of sulfate. Production of chloride ion is high at the start of flooding. It could be because of balancing ion charges on the rock surface. But after a while, chloride started the normal trend as before and continued. About sulfate ion, interestingly, sulfate concentration in SW is about eight times than FW (Table 6). In the FW case, sulfate was produced from the beginning in a high concentration. But in this test, with higher entrance concentration, sulfate is consumed through the flooding process. Because of the repeatability of experiments, this phenomenon cannot be a coincidence. The reason for this phenomenon could be because of other anion concentrations (non-active anions). If we take a look back to Table 6 , it is obvious that other anion concentrations are so higher in FW than SW. These anions would disturb the diffuse layer and reduce the exchange density of sulfate ion. So sulfate ions would be outflowed. So the ratio between ion concentrations would be an important parameter affecting the diffuse layer and wettability alteration mechanism (Figs. 24, 25, 26, 27).

At EXP\#3, SW5000 and SW2000 were used at the flooding process. All trends of outflow ions are the same as before and according to the proposed mechanism: consumption of sodium, production of chloride, consumption of sulfate and magnesium, and production of calcium. The amount of $\mathrm{C} / \mathrm{CO}$ for sodium, magnesium, and sulfate is greater than one, but the total trend is similar. This phenomenon could be because of the TDS difference between SW5000 and FW
Fig. 24 EXP\#3 core A outflow analysis (SW5000 injection)

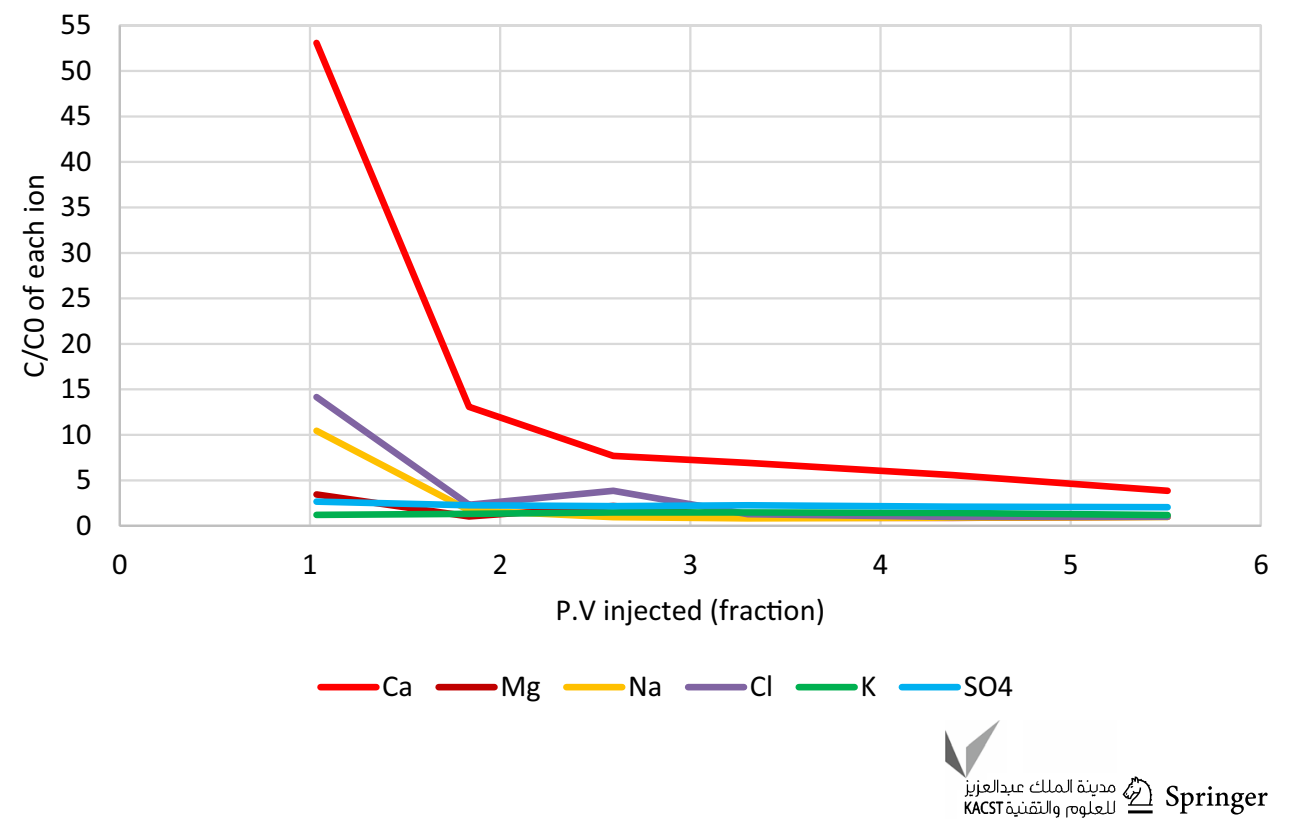


Fig. 25 EXP\#3 core A outflow analysis (SW5000 injection - original scale)
Fig. 26 EXP\#3 core B outflow analysis (SW5000 injection)
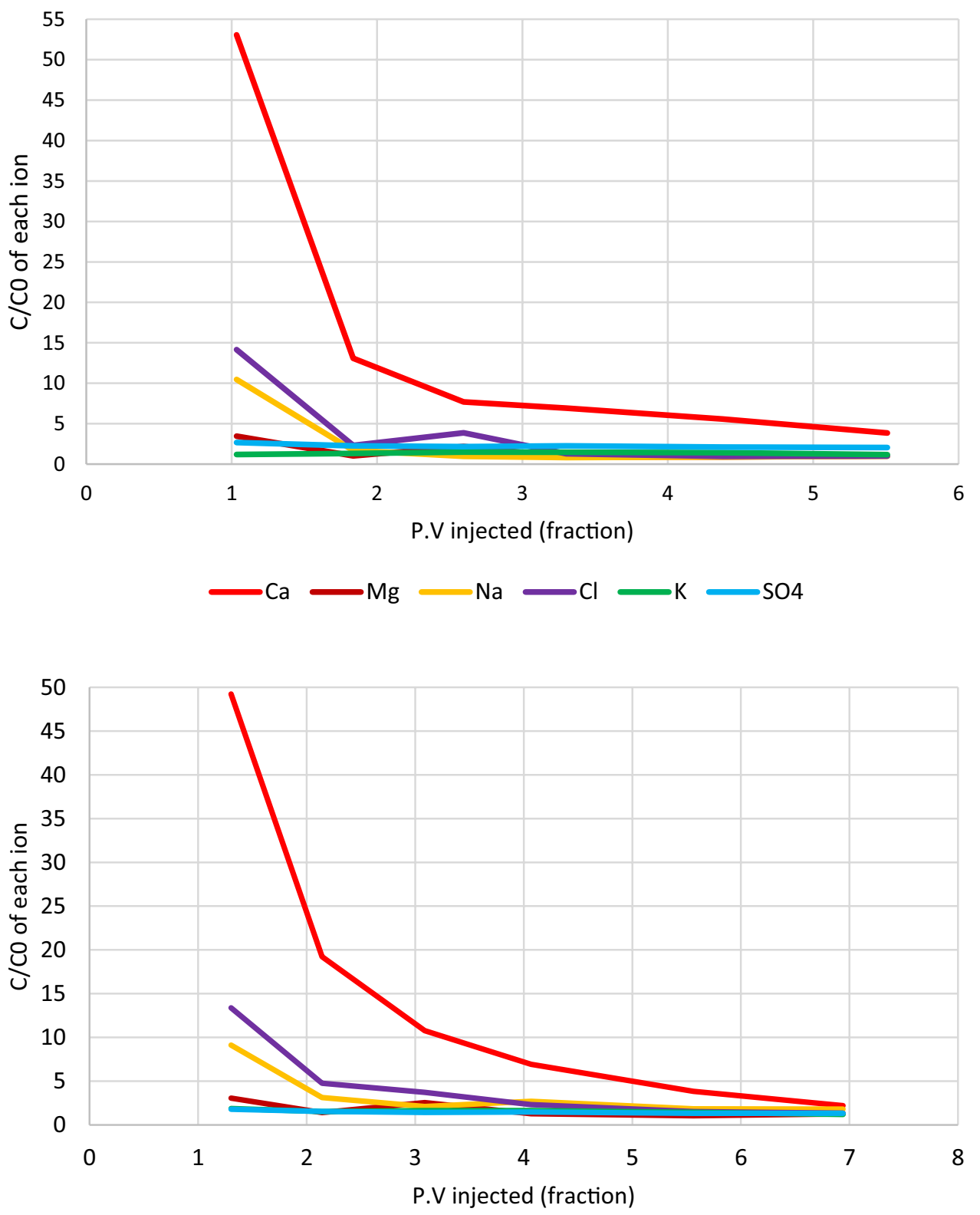

$\longrightarrow \mathrm{Ca} \longrightarrow \mathrm{Mg} \longrightarrow \mathrm{Na} \longrightarrow \mathrm{Cl} \longrightarrow \mathrm{K} \longrightarrow \mathrm{SO}$

as initial water saturation in each core plug (TDS $=5,000$ to $\mathrm{TDS}=223,969$ ) and the exchange capacity of each ion in the diffuse layer. So ions would be produced to stabilize the overall ion composition in the rock surface (Figs. 28, 29).

In EXP\#4, SW2000 flooded followed by SW5000. In addition to investigating the wettability alteration, the possibility of injecting higher-salinity water after a lower one was the goal of this experiment. Now let us see what would happen in ionic composition at the outflow. Outflow trends are similar to SW5000. Magnesium, sulfate, sodium, chloride, and calcium all behave as expected. Like
EXP\#3, $C / C 0>1$ at the start of flow is because of difference in TDS and ionic composition, but overall trends are as expected. The reason is due to diffuse layer thickness reduction. It would be stabilized easier and faster than the injection of a LowSal brine after a high-salinity brine. About the second part of EXP\#4, some ions were consumed with the normal trend, and nothing was weird except that consumption at higher salinity. It was temporary, and after a while, $C / C O$ tends to unity. Concerning the recovery discussed before, this consumption affected a little production. 
Fig. 27 EXP\#3 core B outflow analysis (SW5000 injection - original scale)
Fig. 28 EXP\#4 core A outflow analysis
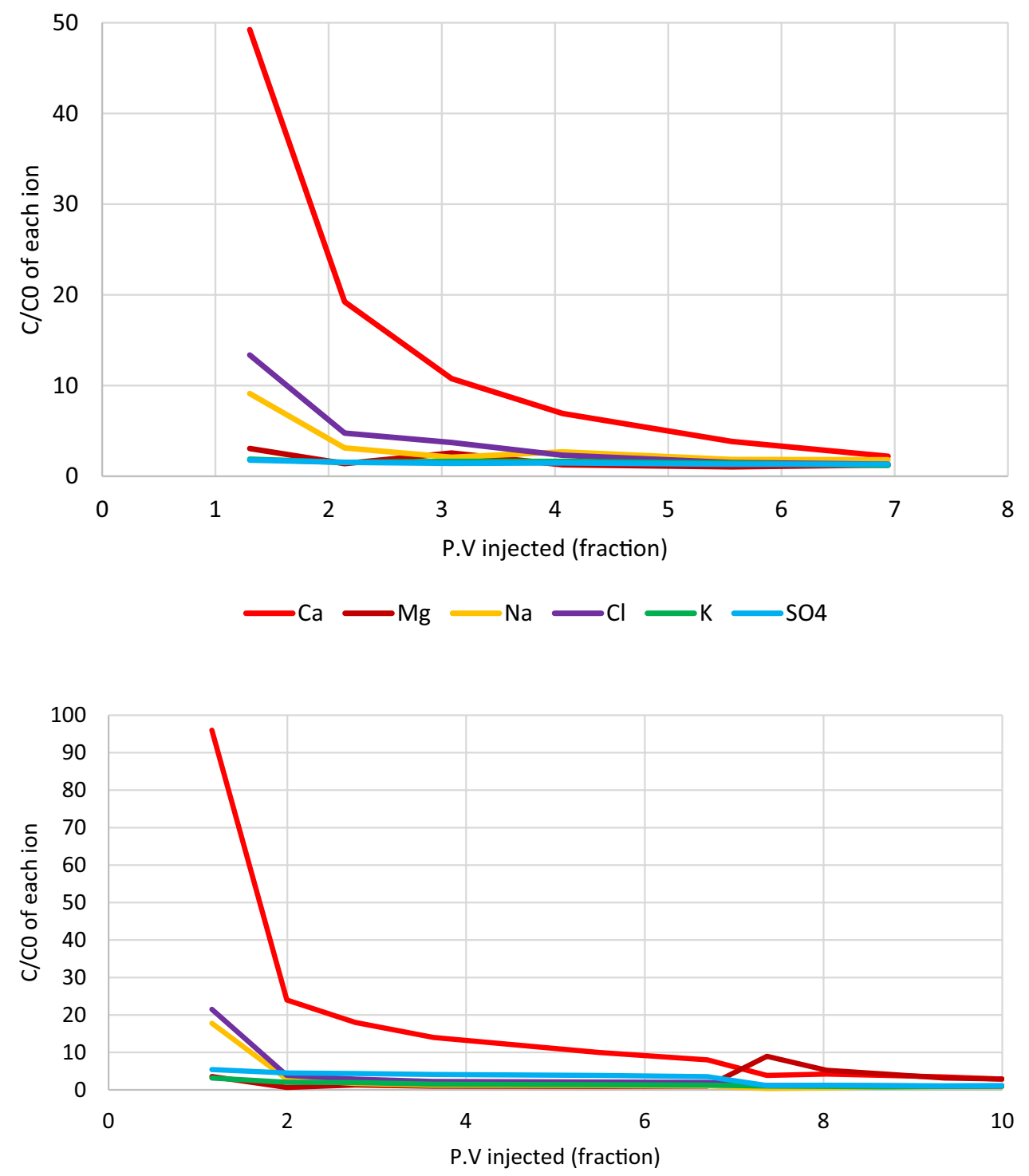

$\longrightarrow \mathrm{Ca} \longrightarrow \mathrm{Mg} \longrightarrow \mathrm{Na} \longrightarrow \mathrm{Cl} \longrightarrow \mathrm{K} \longrightarrow \mathrm{SO} 4$

\section{Smart water effect on wettability alteration}

All previous studies said that sulfate ion is one of the most important ions in the smart water wettability alteration process (Hosseini et al. 2018). With a closer look at MIE and double-layer mechanisms, it is questionable that "Is sulfate ion such an amazing ion?". This question will be more interesting when the two above mechanisms discussed sulfate ion as an agent to neutralize the surface charge. Previous works (Souraki et al. 2018) showed that sulfate ion concentration can affect wettability alteration spectacularly but other negative ions such as $\mathrm{Cl}^{-}$and $\mathrm{HCO}_{3}^{-}$could not affect the mechanism. So what is the difference between these ions? As a chemical view, some important factors can make difference between ions (Hosseini et al. 2018):

\section{- Electronegativity}

Electronegativity is a measure of the tendency of an atom to attract a bonding pair of electrons. The Pauling scale is the most commonly used. Fluorine (the most electronegative element) is assigned a value of 4.0, and values range down to cesium and francium which are the least electronegative at 0.7 . With the above definition, the tendency of sharing negative charges can be a matter. The interaction of sulfate ion instead of other anions may be because of the difference in electronegativity.

- Solubility constant 
Fig. 29 EXP\#4 core A outflow analysis (original scale)

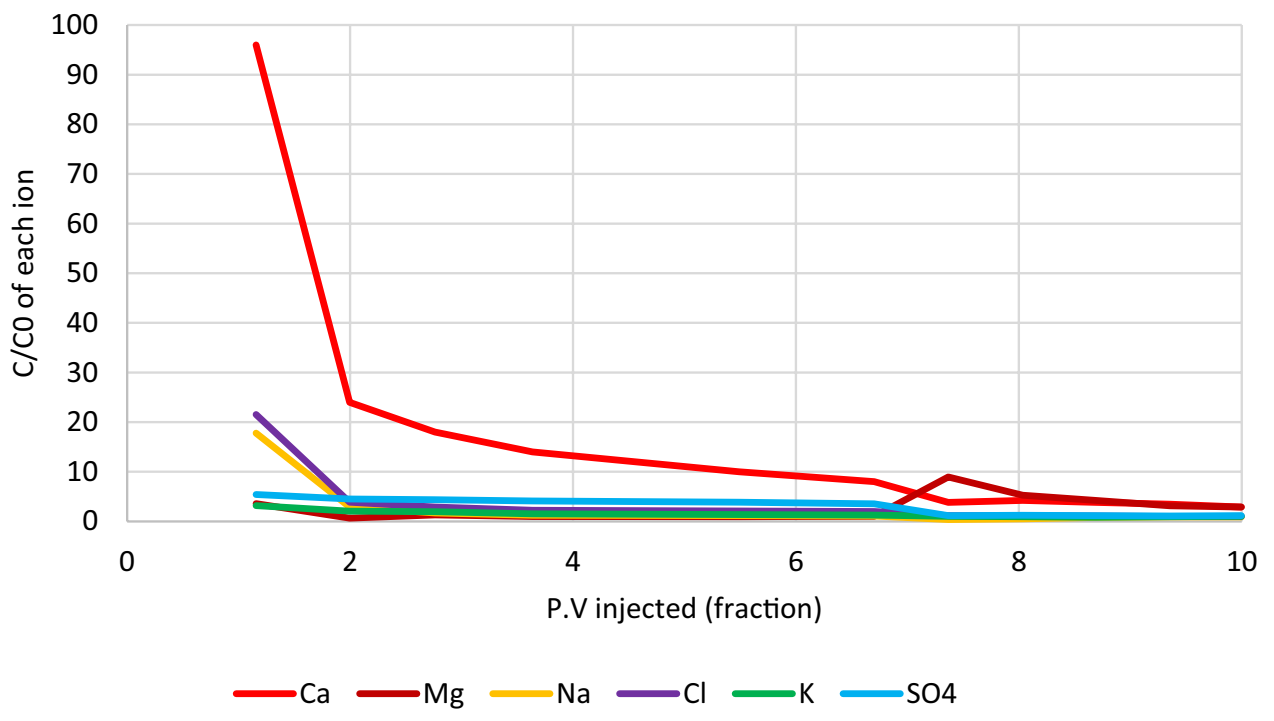

Solubility product constants are used to describe saturated solutions of ionic compounds of relatively low solubility. A saturated solution is in a state of dynamic equilibrium between the dissolved, dissociated, ionic compound and the undissolved solid. The amount of solubility of salt can be achieved from the solubility product. The amount of solubility of sulfate and even the possibility of deposition can affect wettability alteration.

\section{- Charge of ion}

Sulfate ion has a charge of minus two. In MIE and double-layer mechanisms, the charge of ions played a very important role. So maybe the amount of negative charge can affect the process.

- Geometric shape
Concerning all the above-mentioned possible reasons, certainly, the most important role was played by the geometrical shape of ion and the amount of space used. The possibility to have an ion with equal charge and solubility with sulfate is not too low, but chemical reactions are too dependent on the geometrical shape of ions. For all the above possible reasons, phosphate anions seem to be a good choice. Having a similar geometrical shape, oxygen bound and even electronegativity of atoms could make phosphate ions a noticeable case. Among the phosphate ions $\left(\mathrm{PO}_{4}{ }^{3-}, \mathrm{HPO}_{4}{ }^{2-}\right.$, and $\left.\mathrm{H}_{2} \mathrm{PO}_{4}{ }^{-}\right), \mathrm{H}_{2} \mathrm{PO}_{4}{ }^{-}$has a bigger solubility constant. Other ones have not sufficient solubility constant and would deposit in porous media and plug pore throats. So it was decided to use $\mathrm{H}_{2} \mathrm{PO}_{4}{ }^{-}$as an alternative ion for sulfate. If the results show a near or even more wettability alteration, the mechanisms could be challenged and updated (Fig. 30).

Fig. 30 The geometric shape of a $\mathrm{SO}_{4}{ }^{2-}$ b $_{2} \mathrm{PO}_{4}^{-}$
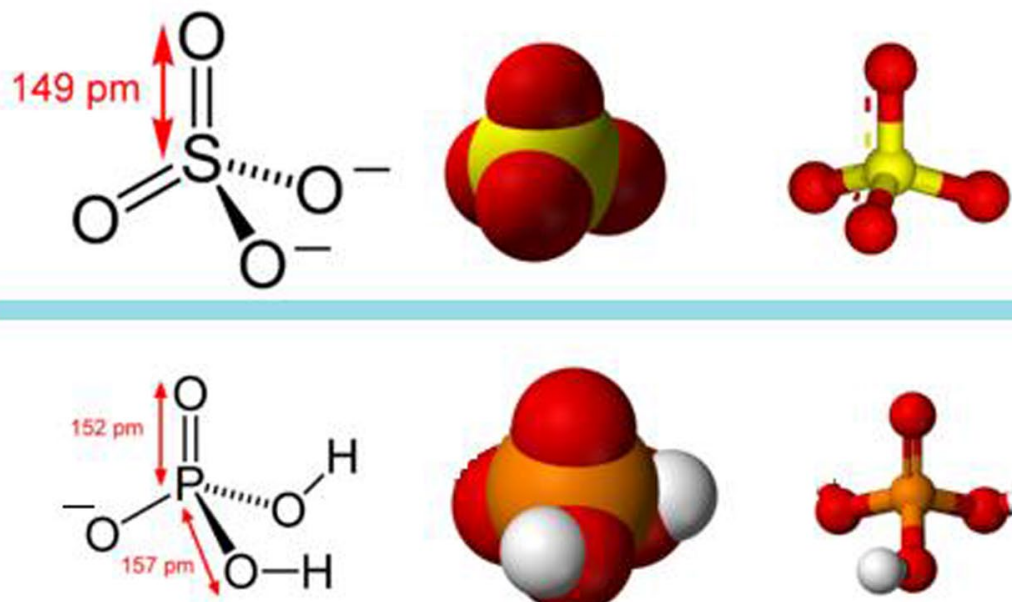

a
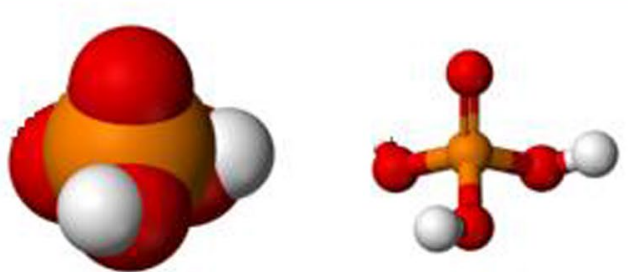


\section{Recovery improvement}

Because of the second set of experiments done on different core plugs, the recovery cannot be a proper scale for comparison with the sulfate case. But it can give us a shallow look at what happened if sulfate ion is substituted with phosphate (Fig. 31).

The source of error could be because of using the results of real seawater. Surely, real seawater has some natural surfactant, so it was better to use synthetic seawater as a basis for comparison. Summary of recovery by a different type of rocks by SW2000 and SW1S and SW2S is given in Table 11.

\section{Relative permeability change}

To know what happened by using phosphate ion instead of sulfate, the relative permeability of core plug AA was compared with core plug A that has the same XRD test, and core plug BB with core plug B. Results are shown in Figs. 32 and 33. As it is obvious, wettability alteration by injected water with and without sulfate and phosphate
Fig. 31 Recovery factor of

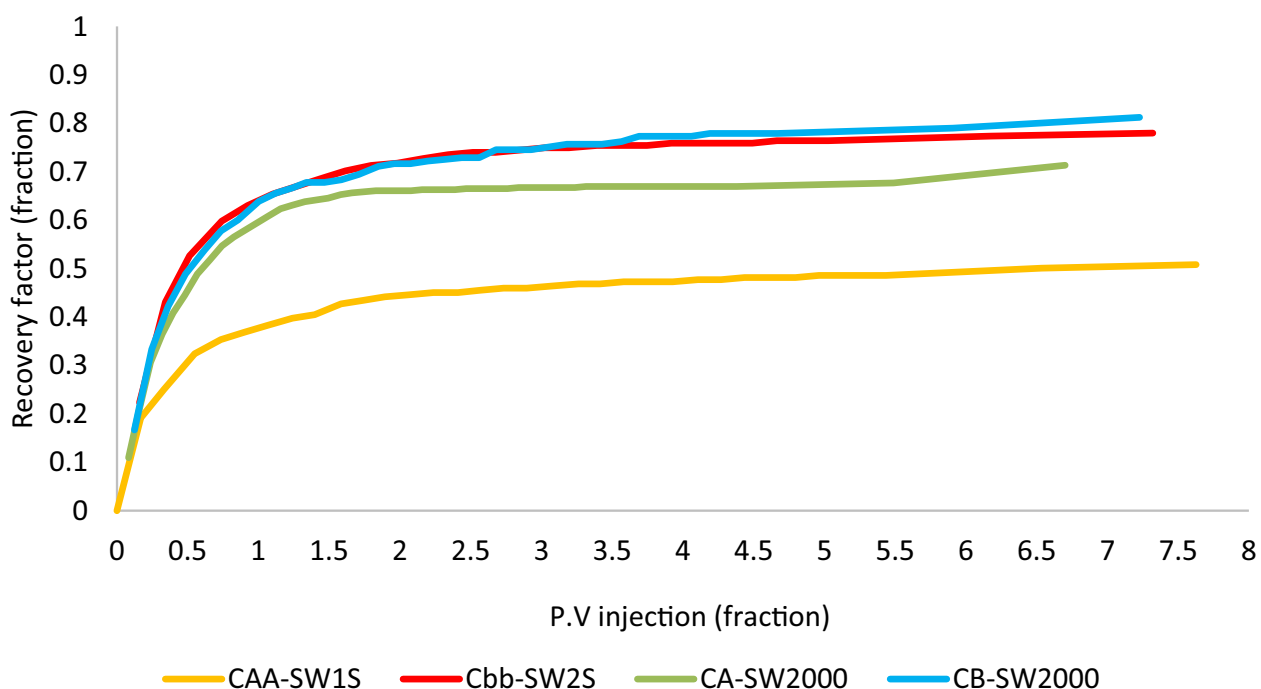

Table 11 Summary of second step core flood experiment in comparison with first one SW2000

Fig. 32 Relative permeability curves of core AA with SW1S, compared with core A flooded by SW and SW2000

\begin{tabular}{lllll}
\hline No. of experiments & Core plug & Water injection & Injection step & $\begin{array}{l}\text { Amount of } \\
\text { recovery (\%) }\end{array}$ \\
\hline EXP\#4 & A & SW2000 & First injection & 71.33 \\
EXP\#4 & B & SW2000 & First injection & 81.22 \\
EXP\#5 & AA & SW1S & First injection & 77.99 \\
EXP\#6 & BB & SW2S & First injection & 50.81 \\
\hline
\end{tabular}

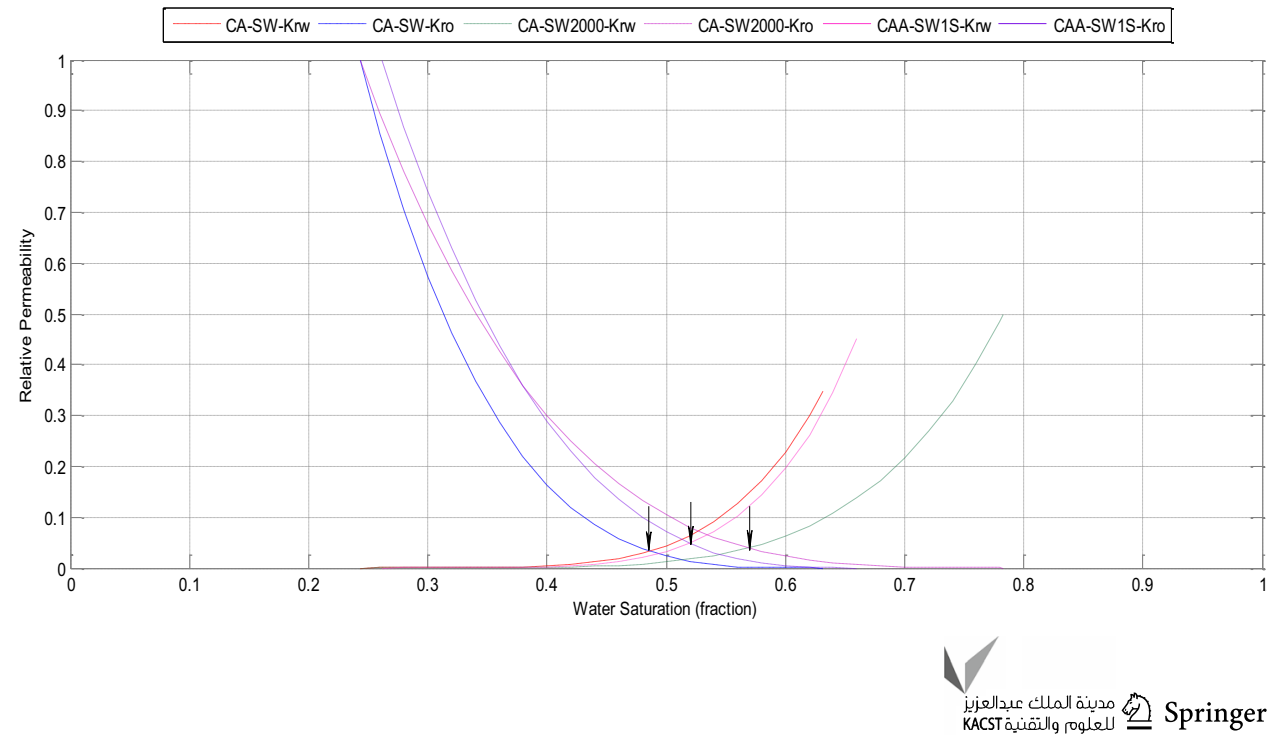


Fig. 33 Relative permeability curves of core BB with SW2S, compared with core B flooded by SW and SW2000

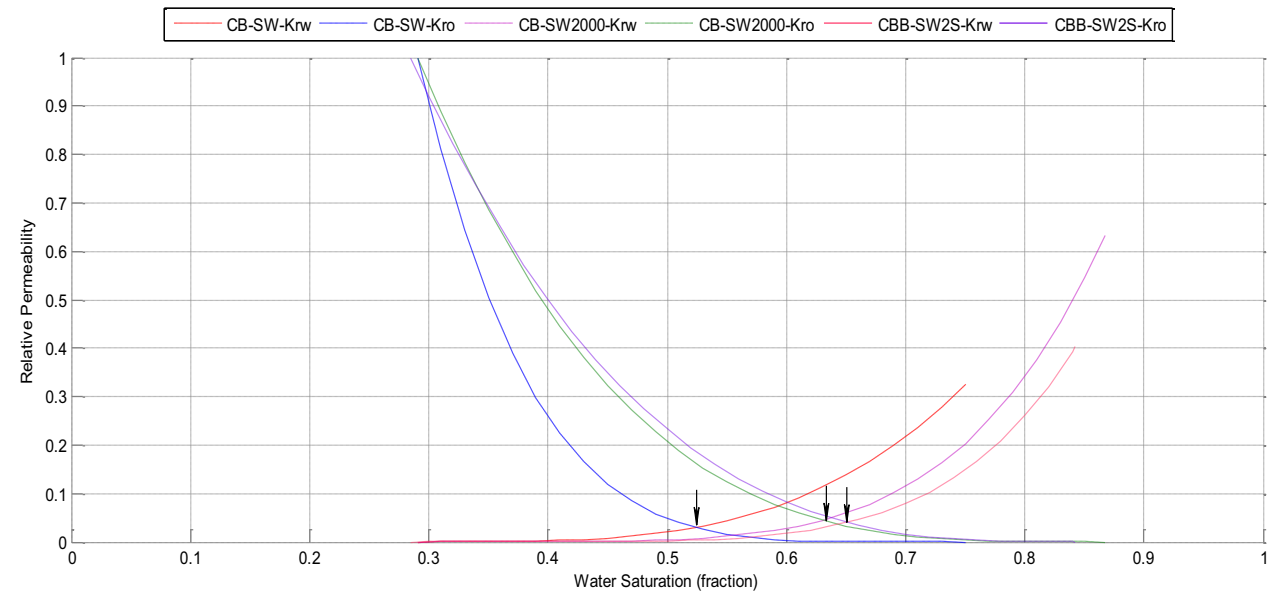

using SW2S is more than SW1S. SW2S has a wettability alteration even more than SW2000, while SW2000 has some natural surfactant too. This wettability modification can be explained by the shape and charge of phosphate ion. In SW1S, there is as much phosphate in brine as SW2000, and in SW2S this amount is twice SW2000. So it was desired that negative phosphate ions be more effective in SW2S as it is approved by relative permeability alteration (Figs. 32 and 33). The reason for better performance using SW2000 instead of SW1S could be the net charge of phosphate ions. $\mathrm{H}_{2} \mathrm{PO}_{4}{ }^{-}$has a negative charge of -1 , while in sulfate ions it is -2 . So sulfate ions would decrease rock surface charge more than phosphate, and then magnesium and calcium would separate the carboxylate group more easily. In SW2S, the condition is changed and the net negative charge of phosphate ion would be the same as sulfate in injection brine.
The difference between phosphate and sulfate affects the diffuse layer too. Due to more concentration of phosphate ion, exchange density would approach maximum exchange capacity more than sulfate. So phosphate has more adsorption due to more concentration. Besides, phosphate ion has a more tendency to share charge in comparison with sulfate. It would help phosphates to have a better wettability alteration than sulfate.

\section{The possible effect of interfacial tension (IFT) on recovery and relative permeability}

For IFT and contact angle measurements, synthetic diluted seawater up to 2,000 ppm (SSW2000) was used to eliminate the possible effect of natural surfactants. The final results are shown in Fig. 34.
Fig. 34 IFT of different types of smart water use

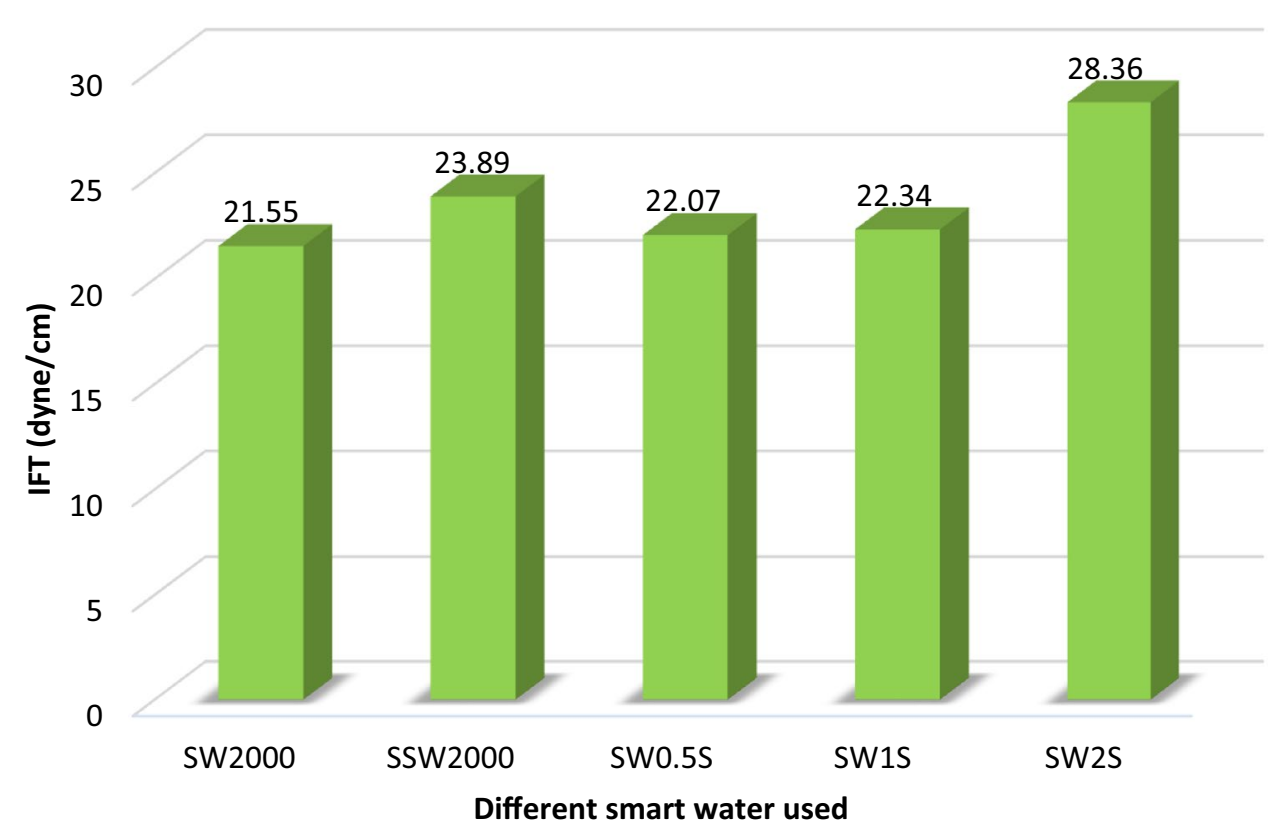


The mechanism of IFT reduction by SW1S and SW2S is just like what is discussed in the first step. In SW1S and SW0.5S, the concentration of phosphate is low and the total impact of negative charge would be lower than sulfate (because of less negative charge). But in SW2S, phosphate concentration somehow meets a critical concentration. Due to more space needed by phosphate and higher concentration, phosphates would occupy space around the oil droplet and reduce the tendency of cations to join the carboxyl group. This would affect IFT to increase as described in Fig. 35.

\section{Contact angle change}

Contact angle measurements approved the results of relative permeability changes. The proposed mechanism is as discussed for relative permeability. The results are shown in Fig. 36.

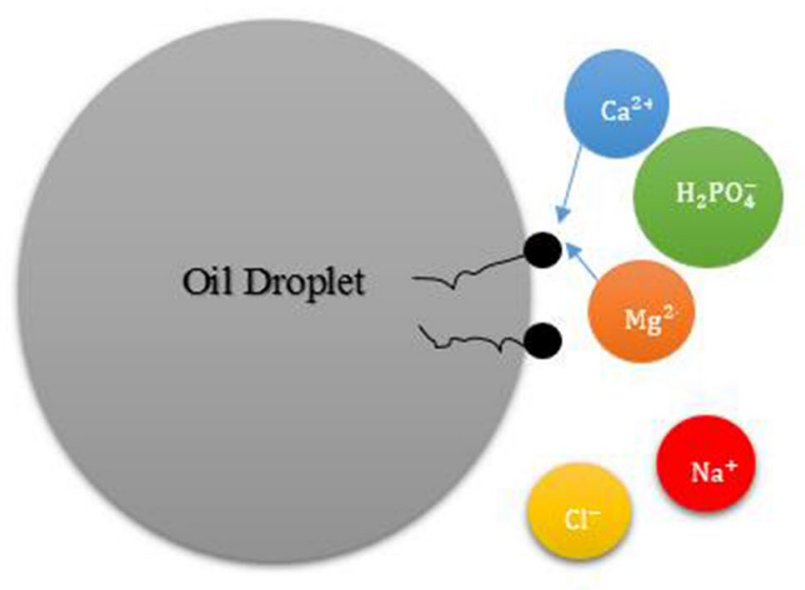

Fig. 35 IFT mechanism using phosphate ion

\section{Outflow analysis}

After gathering the outflow of core flooding experiments, outflows are divided into four samples to analyze. In this step, $\mathrm{pH}$ of outflows had been analyzed.

$\mathrm{Ph}$ As said before, $\mathrm{pH}$ increasing is a result of the smart water wettability change mechanism. As seen in the first step, $\mathrm{pH}$ increased from 0.1 to 2 . In the phosphate case, it was re-checked and the results confirm $\mathrm{pH}$ increasing (Fig. 37). The increase was about $1-2$ units. The $\mathrm{pH}$ stability near 7.5 was seen again in this step too, and equilibrium in dissolving carbonate and consuming sodium and hydrogen was confirmed again.

\section{Comparison of mechanisms}

Based on the previous work, smart water wettability alteration mechanisms work altogether and it is possible to see all the effects of mechanisms in one test as seen in $\mathrm{pH}$, and ion analysis of tests was performed in this study. A summary of the possible mechanism according to previous work and results of this work is as follows. First of all, the salting-in (and salting-out) effect occurred, such that ions in injection water diffuse from a diffuse layer to a rock surface (because of concentration difference). Active ions would be near the surface. Then, specific anions deposited on the rock surface (because of the positive charge of carbonated rocks) and the surface charge would tend to the negative sign. In this time, carboxylate group would separate from the rock surface. Now, it is time for cations; in high temperatures magnesium would be deposited on the surface to neutralize charge and calcium would stock to the carboxyl group. The bound between carboxylate and calcium is not a chemical bound, and they are near
Fig. 36 Contact angle alteration by using different smart water

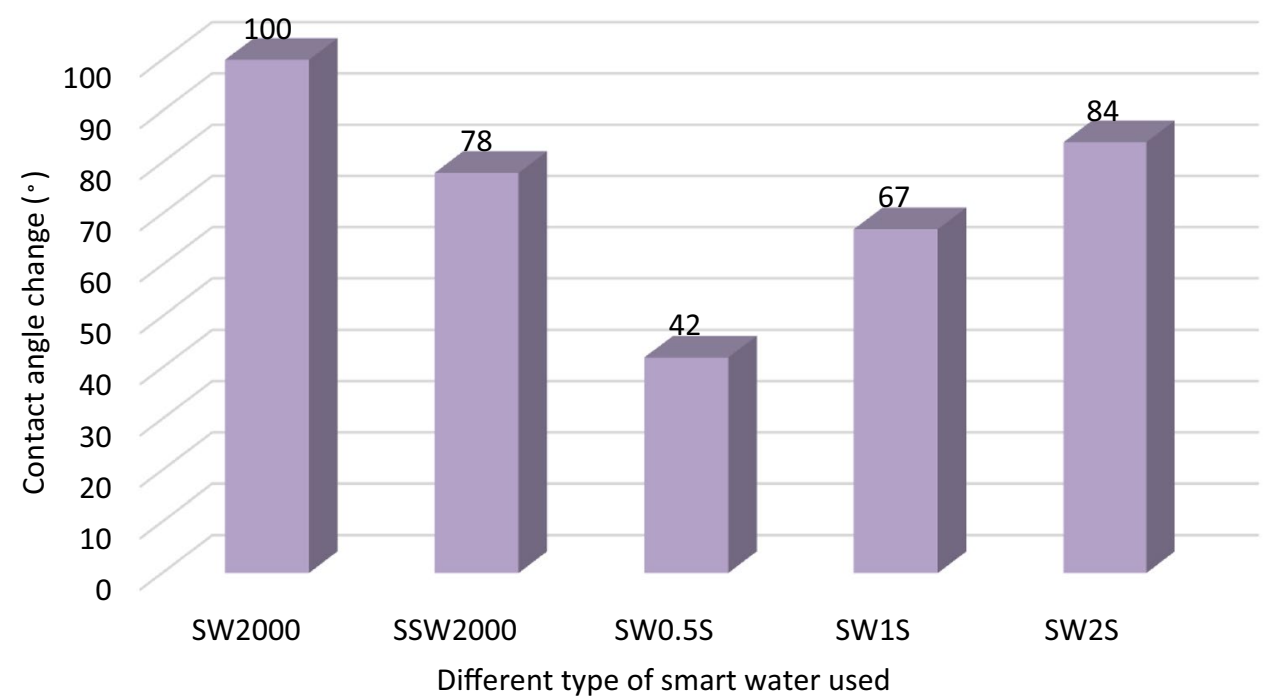

Different type of smart water used 
Fig. $37 \mathrm{pH}$ difference of outflow and inflow of second step core flooding

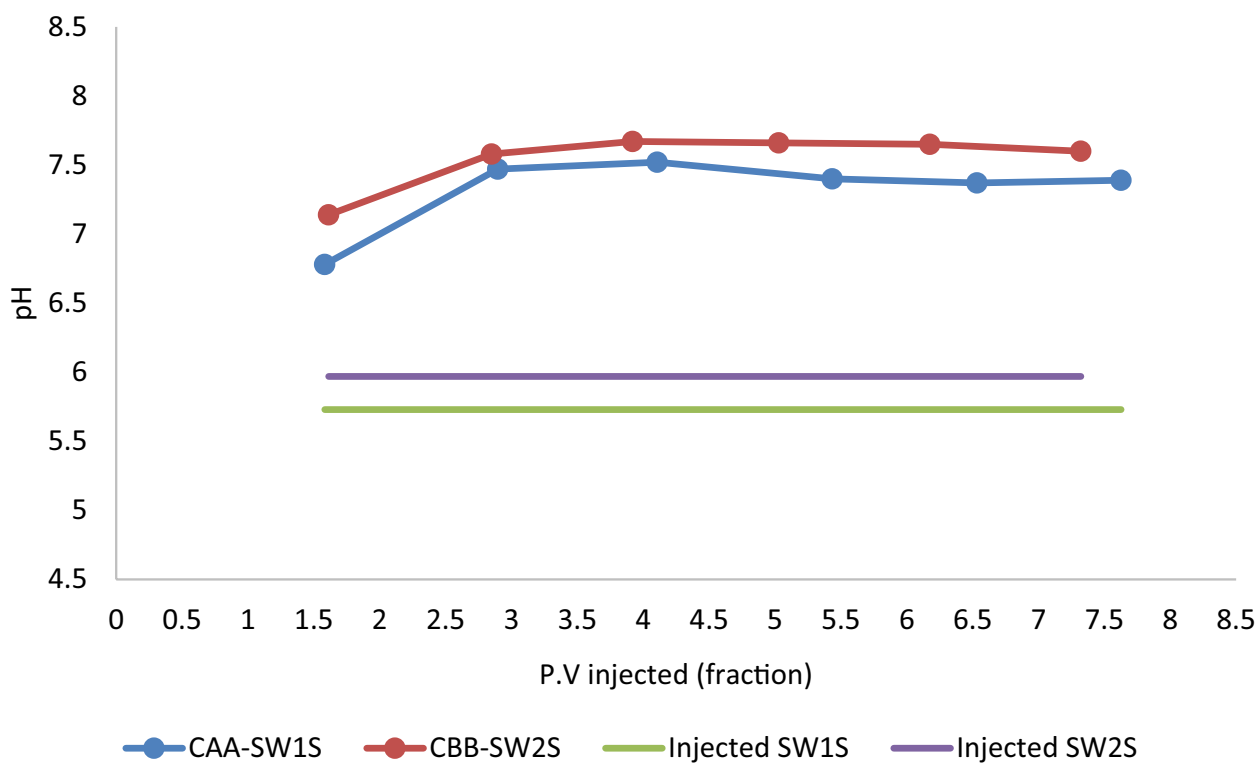

to each other while some water molecules cover them. With the outflow of oil, calcium would come out and the outflow concentration of magnesium decreases. In this process, cations would leave a diffuse layer. So positive charge would decrease and compensate with sodium and hydrogen. Consumption of sodium and hydrogen would release some hydroxide groups affecting $\mathrm{pH}$ increasing in the outflow. In this mechanism, potential determining (active) ions are:

- Specific cations: $\mathrm{Ca}^{2+}, \mathrm{Mg}^{2+}$ that is crucial in the wettability alteration process

- Specific anions:

Anions have no impact on the carboxylate group directly. Anions should neutralize the surface charge. $\mathrm{SO}_{4}{ }^{2-}$ and $\mathrm{H}_{2} \mathrm{PO}_{4}{ }^{-}$are examples of negative ions that can participate in the wettability alteration process. Scientifically, each anion that has the same geometric shape, size, and electronegativity like $\mathrm{SO}_{4}{ }^{2-}$ and $\mathrm{H}_{2} \mathrm{PO}_{4}{ }^{-}$can participate in this process. (Practically, it is not investigated but with the results of this project, it may be practical.) However, $\mathrm{SO}_{4}{ }^{2-}$ could be better than $\mathrm{H}_{2} \mathrm{PO}_{4}{ }^{-}$in equal concentration because of the more negative charge.

\section{Conclusions}

The purpose of this study is to investigate the injection of low-salinity and smart water to alter wettability and improve recovery in one of the Iranian carbonate oil reservoirs. Some of the conclusions of this research work are as follows:
1. Injection of low-salinity water followed by higher-salinity water would lead to greater wettability alteration and total recovery. So it is better to use low-salinity water as the secondary recovery process.

2. According to the measurements of relative permeability, contact angle, and ion analysis, formation water cannot effectively improve smart water wettability alteration. In other words, it is necessary to have a brine with different ion ratios for the desired wettability alteration (i.e., the difference between ion ratios would cause different degrees of wettability alteration).

3. The preferred outflow $\mathrm{pH}$ of smart water injection would be around 7.5 to 8 , because of ion balance in porous media. This amount cannot be crucial in the design of surface and wellbore facilities, because 7.5 to 8 is near to neutrality, and facilities could tolerate this amount of $\mathrm{pH}$.

4. The presence of non-active ions such as $\mathrm{Na}^{+}$in smart water is important and cannot be underestimated. In the smart water wettability alteration mechanism, water at optimum salinity should have all anions and cations in a proper ratio. Substituting $\mathrm{Na}^{+}$and $\mathrm{H}^{+}$in the diffuse layer after deposition of $\mathrm{Ca}^{2+}, \mathrm{Mg}^{2+}$ would cause releasing $\mathrm{OH}^{-}$and increasing outflow $\mathrm{pH}$.

5. Specific ions can be effective for wettability alteration in smart water injection. Magnesium and calcium are two important active cations. Specific anions could be $\mathrm{SO}_{4}{ }^{2-}$ and $\mathrm{H}_{2} \mathrm{PO}_{4}{ }^{-}$which act as a neutralizing agent to reduce surface charge in carbonated reservoirs.

6. Wettability alteration by smart water is a very complicated mechanism. Although the experimental results demonstrate that dilution and low-salinity water injection are beneficial in achieving better oil recovery, it is 
difficult technically to introduce a unique composition of ions in smart water for wettability alteration for all types of rocks because of variable factors affecting the process, such as A.N, B.N, ingredients of reservoir rock, temperature, and so on.

\begin{abstract}
Acknowledgements The authors would like to thank Sarvak Azar Engineering and Development Company (SAED), Oil Industries Engineering and Construction Group (OIEC) for providing crude oil, and Dr. Ali Akbar Eftekhari from the Danish Hydrocarbon Research and Technology Centre (DHRTC), Technical University of Denmark (DTU), for his assistance and advice in matters concerning the experimental setup and procedure.
\end{abstract}

Open Access This article is licensed under a Creative Commons Attribution 4.0 International License, which permits use, sharing, adaptation, distribution and reproduction in any medium or format, as long as you give appropriate credit to the original author(s) and the source, provide a link to the Creative Commons licence, and indicate if changes were made. The images or other third party material in this article are included in the article's Creative Commons licence, unless indicated otherwise in a credit line to the material. If material is not included in the article's Creative Commons licence and your intended use is not permitted by statutory regulation or exceeds the permitted use, you will need to obtain permission directly from the copyright holder. To view a copy of this licence, visit http://creativecommons.org/licenses/by/4.0/.

\section{References}

Al-Sarihi A, Russell T, Bedrikovetsky P, Zeinijahromi A (2019) Fines stabilization by Ca ions and its effect on LSW injection. Energy Fuels 33(11):10775-10786. https://doi.org/10.1021/acs.energ yfuels.9b02683

Amirian T, Haghighi M, Mostaghimi P (2017) Pore scale visualization of low salinity water flooding as an enhanced oil recovery method. Energy Fuels 31(12):13133-13143. https://doi.org/10.1021/acs. energyfuels.7b01702

Amirian T, Haghighi M, Sun Ch, Armstrong RT, Mostaghimi P (2019) Geochemical modeling and microfluidic experiments to analyze impact of clay type and cations on low-salinity water flooding. Energy Fuels 33(4):2888-2896. https://doi.org/10.1021/acs.energ yfuels.7b01702

Atthawutthisin N (2012) Numerical simulation of low salinity water flooding assisted with chemical flooding for enhanced oil recovery. Department of Petroleum Engineering and Applied
Geophysics, Norwegian University of Science and Technology (NTNU)

Austad T, Strand S, Høgnesen E, Zhang P (2005) Seawater as IOR fluid in fractured chalk. In: SPE international symposium on oilfield chemistry, 2005. Society of Petroleum Engineers

Austad T, RezaeiDoust A, Puntervold T (2010) Chemical mechanism of low salinity water flooding in sandstone reservoirs. In: SPE improved oil recovery symposium, 2010. Society of Petroleum Engineers

Bartels W-B, Mahani H, Berg S, Hassanizadeh SM (2019) Literature review of low salinity water flooding from a length and time scale perspective. Fuel 236:338-353

Berg S, Cense A, Jansen E, Bakker K (2010) Direct experimental evidence of wettability modification by low salinity. Petrophysics 51:05

Eftekhari AA (2019) Carbonated water injection in the North Sea chalk reservoirs: energy analysis and environmental assessment. In: Proceedings of the 20th European symposium on improved oil recovery (IOR 2019) European Association of Geoscientists and Engineers, Pau, France

Hosseini E, Hajivand F, Yaghodous A (2018) Experimental investigation of EOR using low-salinity water and nanoparticles in one of the southern oil fields in Iran. Energy Sources Part A Recov Util Environ Eff 40(16):1974-1982. https://doi.org/10.1080/15567 036.2018 .1486923

Souraki Y, Hosseini E, Yaghodous A (2018) Wettability alteration of carbonate reservoir rock using amphoteric and cationic surfactants: experimental investigation. Energy Sources Part A Recov Util Environ Eff 41(3):349-359. https://doi.org/10.1080/15567 036.2018 .1518353

Sun C, McClure JE, Mostaghimi P, Herring AL, Meisenheimer DE, Wildenschild D, Berg S, Armstrong RT (2020) Characterization of wetting using topological principles. J Colloid Interface Sci 578:106-115. https://doi.org/10.1016/j.jcis.2020.05.076

Taheriotaghsara M, Bonto M, Eftekhari AA, Nick HM (2020) Prediction of oil breakthrough time in modified salinity water flooding in carbonate cores. Fuel 274:117806. https://doi.org/10.1016/j. fuel.2020.117806

Zolfagharloo A, Hosseini E, Ebrahimian E, Moradi S (2018) Experimental investigation of the effect of palmitic acid as an inhibitor on the particle size of asphaltenes flocs using imaging techniques. Energy Sour A Recov Util Environ Effects 40(1):108-114. https ://doi.org/10.1080/15567036.2017.1405118

Publisher's Note Springer Nature remains neutral with regard to jurisdictional claims in published maps and institutional affiliations. 